\title{
A Theoretical Perspective on Multilateral Agreements on Investment
}

\author{
Dieter Urban*
}

July 3, 2006

\begin{abstract}
This study provides a rationale for a multilateral investment agreement (MAI), an explanation of its obstacles in implementation, and a description of its welfare implications with particular focus on least developed countries (LDCs). A MAI negotiated by a club of governments with heterogeneous objectives reduces a time inconsistency problem of rent extraction from MNEs by governments but constitutes an information externality on non-members. At the same time, it is instable, and a regime emerges where there are many different agreements comparable to bilateral investment treaties (BITs). However, an appropriately designed MAI is world-welfare improving compared to a regime of BITs by alleviating a political economy distortion.
\end{abstract}

JEL Reference: F13, F23, O19.

Keywords: Foreign Direct Investment, International Agreements, Adverse Selection.

*Institute for International Economic Theory, FB03, Johannes Gutenberg-University Mainz, 55099 Mainz, Germany. Tel: ++49 (0) 613139 25140. Email: dieter.urban@uni-mainz.de. 
July 3, 2006

\title{
A Theoretical Perspective on Multilateral Agreements on Investment
}

\begin{abstract}
This study provides a rationale for a multilateral investment agreement (MAI), an explanation of its obstacles in implementation, and a description of its welfare implications with particular focus on least developed countries (LDCs). A MAI negotiated by a club of governments with heterogeneous objectives reduces a time inconsistency problem of rent extraction from MNEs by governments but constitutes an information externality on non-members. At the same time, it is instable, and a regime emerges where there are many different agreements comparable to bilateral investment treaties (BITs). However, an appropriately designed MAI is world-welfare improving compared to a regime of BITs by alleviating a political economy distortion.
\end{abstract}

JEL Classification: F13, F23, O19.

Keywords: Foreign Direct Investment, International Agreements, Adverse selection. 


\section{Introduction}

An important part of globalization is the activity of multinational enterprises (MNEs). The explosion of such activity in recent years had an impact not only on the efficiency of world wide production sharing but also on relative factor incomes. The resulting conflict of interest across owners of different factors may stimulate policy reactions to globalization both on a national and an international level where some governments favor liberalization and others regulation of foreign direct investment (FDI).

In fact, there was a trial to implement a multilateral agreement of investment (MAI) to liberalize FDI. In the year 1995, negotiations for a MAI were initiated by the OECD among experts and a draft proposal emerged. There are few basic elements that make up an international investment agreement: the definition of the investments covered by the agreement, the rules aimed at providing protection against expropriation, those directed at liberalizing investment in a non-discriminatory way, and a set of rules defining a dispute settlement mechanism (DSP). ${ }^{1}$ When the draft became known to the public, it received criticism by several interest and opinion groups within advanced countries (NGOs, environmentalists, trade unions) and a fierce opposition by some developing countries. ${ }^{2}$ Eventually, this agreement failed on an OECD summit in 1998, but there was at the same time a surprising explosion in bilateral investment treaties (BITs) throughout the 90ies.

The purpose of this study is first to explain, why some Least Developed Countries (LDCs) have complained about the OECD negotiations, although they were free to join or opt out. Second, why was the set of negotiating countries enlarged during the course of negotiations and why were a lot of exemptions to FDI liberalization added to the MAI proposal afterwards? Third, why did the initial negotiators lose interest in the agreement and the proposal failed? Fourth, why do we observe instead an explosion of BITs? And

\footnotetext{
${ }^{1}$ The OECD MAI proposal contemplated investment defined in a broad sense (all FDIs plus portfolio investment), non discrimination consistent with the most foavored nation and national treatment principles, and a DSP working both on a State-State basis and on an Investor-State basis. Moreover, the final draft included a series of general and country-specific exceptions (OECD (1998)). See also UNCTAD (1999), p.128-137, for a concise description of the MAI.

${ }^{2}$ In particular, India, Indonesia, and Malaysia were critical. The vigour with which the representatives of these countries reacted against the MAI draft can be found in the words of a former finance minister of India : "You have to remember our history as a colony. The East India Company came here as a trader and ended up owning the country." (The Economist, 1998).
} 
finally, is there a role for a multilateral investment agreement to improve world welfare if appropriately designed?

We will answer these questions in a model, where FDI is driven by relative factor endowments and political risk. Political risk arises from change in government and incomplete information of MNEs on the new governments' attitude towards FDI before experiencing the new policy. Because MNEs base their location decision in this stage on some average perception, they loose from businesses in illiberal countries but gain from those in liberal ones. Hence, resources are transferred indirectly from countries that are liberal towards FDI to those that are not. This creates the incentive for liberal countries to create a multilateral investment agreement that enforces a minimum standard of FDI liberalization. Since all countries in the world are free to join or opt out, their membership choice reveals information on their type and reduces the indirect subsidy by causing investment diversion towards members.

While this can explain the protest of some outsiders to the negotiation, it also explains why the agreement is instable, because the same conflict of interest applies among negotiating countries. Hence, a regime will emerge where agreements are formed only among countries that are alike in their policy goals concerning FDI. One may view this regime as one of BITs. Still, there is some potential for a multilateral agreement to improve world welfare compared to a regime of BITs. An appropriately designed multilateral agreement bends policies of a self-interested government towards the one that optimizes host-country welfare even if countries are not members, because the threat of investment diversion disciplines the government when acting in its own interest.

When explaining the failure of MAI in 1998, the protest of LDCs was not the only reason - and maybe not the decisive one. There was considerable disagreement among the OECD countries for a number of reasons, as well. We disregard these considerations and focus on the LDC stake in MAI negotiations. ${ }^{3}$

To the best of our knowledge there does not exist a theoretical model in a multicountry setting to discuss the emergence of a multilateral investment agreement. The paper closest to ours by Fernandez-Arias and Spiegel (1997) discusses a regional trade and

\footnotetext{
${ }^{3}$ See Hoekman and Saggi (2000), p. 184ff, for a comprehensive list of reasons.
} 
investment agreement in a three-country world. However, FDI is considered the movement of physical capital across borders, rather than the exertion of control rights across borders, and no discussion is devoted to multilateral agreements. In Markusen (2001), a trade-off of commitment and discretion is formalized where an LDC decides on acceding a MAI. Commitment enhances credibility that promotes FDI. Instead, the loss of discretion can remove a threat of host countries against MNEs and worsen its bargaining position in MNE rent sharing. However, the formation of MAI is not formalized.

There is, however, an informal discussion on MAI, e.g., by Markusen (1998) and Hoekman and Saggi (2000). Hoekman and Saggi (2000) see in MAI an instrument of FDI promotion that constrains countries' control over MNEs. When joining MAI, governments forgo the possibility to shift rents from MNEs to host countries in exchange for using MAI as a commitment device or signal to enhance credibility of an FDI promotion policy. In addition, FDI influences the factor income distribution and affects thereby the political equilibrium in the host country. Markusen (1998) provides an extensive theory-based survey of the LDC stake in MAI. While the basic trade-offs are well understood, our formalization sharpens the understanding of the underlying mechanics in the formation of MAI and its obstacles, and allows to derive a MAI design that is world-welfare superior to the status quo.

There is also some resemblance of our model with Ethier (1998) in that a national political equilibrium driven by income redistribution concerns shapes the governments' bargaining position in international negotiations and is traded off with gains from outsourcing. There is also a discussion of various stages of integration - unilateralism, bilateralism/regionalism, and multilateralism. However, we focus on multilateral investment agreements, while Ethier (1998) restricts the discussion to trade agreements.

There is a huge literature on tax and subsidy competition that may justify multilateral agreements. Multilateralism justified by this literature would regulate FDI and not liberalize it contrary to our model and to the MAI provisions of the OECD draft of MAI. Moreover, the emergence of a multilateral agreement is not explained. ${ }^{4}$

\footnotetext{
${ }^{4}$ Some examples of this literature are Black and Hoyt (1989), Haaparanta (1996), Haaland and Wooten (1999), Haufler and Wooten (1999), and Fumagalli (2000).
} 
The rest of this study is organized as follows. In the next section, we discuss the economic fundamentals of our problem and derive conclusions on the choice of plausible model ingredients. In section 3, we introduce a baseline model of FDI, add a political equilibrium, discuss the implications of a multilateral agreement for the equilibrium, and eventually characterize the equilibrium for a MAI of an exogenous negotiation group. We show then how a MAI of a given negotiation group collapses and a regime of BITs assembles. In section 4, we suggest a MAI design that is world-welfare improving and causes only modest resistance by governments. A discussion of the model robustness is followed in section 5 , and a conclusion is found in section 6 .

\section{Informal Discussion of an FDI Model}

Every FDI theory that explains FDI flows towards LDCs is confronted with the Lucaspuzzle. Despite obvious cost advantages of LDCs, there is too little capital flowing from industrialized countries to LDCs. One potential explanation of Lucas (1990) is political risk - the lack of enforcement of international debt contracts. Other explanations are human capital externalities and monopoly rents of MNEs. Reinhart and Rogoff (2004) have recently argued contrary to Lucas (1990) that political risk is the core cause of the lack of capital flows from rich to poor countries ${ }^{5}$. Extending the notion of political risk to the case of multinational firms, the analogy to default on an international debt contract is expropriation of foreign-firm property. Likewise, delay or reduction of interest payment of a debt contract finds its correspondence in the unexpected extraction of rents from MNE activity. ${ }^{6}$

In the perception of experts, reduction of political risk was one of the main purposes of MAI. For example, a WTO economist justifies the desirability of MAI by "...foreign investors need[s] [of] a legal protection to do business. Without such a protection, the risk of doing business in a foreign country may be so excessive that they decide not to

\footnotetext{
${ }^{5}$ Two stylized facts are provided, among others. First, there is a high negative correlation of serial government debt default and per capita income. Second, private equity markets are highly underdeveloped in poor countries. Both hints at major problems of contract enforcement and property right protection.

${ }^{6}$ See Schnitzer (2002) for a theory of these two forms of international investment in the presence of sovereign risk, i.e. lack of international contract enforcement and expropriation risk.
} 
invest. ... national legislation is often not sufficient to provide adequate security to foreign investors." (Drabek, 1998, p. 5)

There exists an ample literature on a theory of expropriation risk of MNEs. Most of the time it is regarded as some sort of a time inconsistency problem between investor and governments. In this tradition can be found Eaton and Gersovitz (1984), Raff (1992), Doyle and van Wijnbergen (1994), Thomas and Worall (1994), Schnitzer (1999) and Janeba (2002), among others. ${ }^{7}$ However, a time inconsistency problem does not really involve risk, since investors can perfectly foresee the government action. We will add therefore an element of informational uncertainty, by allowing governments to have different types and MNEs to be incompletely informed about it. ${ }^{8}$

We model a political equilibrium within a country as source of this informational asymmetry. The political equilibrium will be the outcome of a power struggle of societies' interest groups. To the extent that FDI inflows benefit some groups and harm others, the outcome of the power struggle will drive political decision making of governments towards more or less liberal FDI policies. Yet, political equilibria are instable, and governments change either as the result of an election outcome in a democracy or a coup d'etat in an authoritarian regime. However, investors learn the type of the new government mostly at a time lag by own experience and the one of their competitors. Even if they learn the type immediately, it will take time to adjust their investments.

There is a well-known mechanics through which FDI causes a conflict of interest among groups of society. FDI inflows have an impact on the distribution of factor income according to vertical FDI theory whenever relative factor intensities of MNEs and local firms do not coincide. ${ }^{9}$ If there is no mechanism in the political system such that

\footnotetext{
${ }^{7}$ Empirical evidence on the nexus of political risk and FDI can be found along at least four lines. First, FDI is lower the larger is direct and indirect taxation (e.g. Hines and Rice, 1994; Devereux and Griffith, 1998). Second, there is evidence that corruption in a country deters FDI (e.g. Wei, 2000). Third, the quality of intellectual property right protection is a determinant of FDI (Lee and Mansfield, 1996). Fourth, political risk measured from surveys of experts and institutional uncertainty obstruct FDI (e.g. Jun and Singh, 1996; Brunetti and Weder, 1998; Gastanaga et al., 1998).

${ }^{8}$ Raff (1992) makes the similar point that expropriation would never be observed if a standard time inconsistency problem was the cause of expropriation risk and introduces also informational asymmetries. However, a different theoretical mechanics is applied that would be too complicated in our setting.

${ }^{9}$ We will draw on model features of vertical FDI theory from Helpman (1984) and Feenstra and Hanson (1996), but resort to a drastic simplification.
} 
winners automatically compensate losers of FDI inflows, then groups of different factor owners will have conflicting interests in attracting or inhibiting FDI. The outcome of the resulting political struggle will shape government decisions on national policies and at a multilateral negotiation. At the same time, the political decision maker has a national policy instrument - the rent extraction through taxation, expropriation, and many other informal measures that affect FDI profits - to steer the amount of FDI inflows compatible with the political equilibrium of the host country. An increase in rent extraction will reduce FDI inflows at the latest when investors have learned the government type by (bad) experience.

There is another impact that FDI inflows have on host country welfare. The extraction of MNE rents creates government revenues. A pure rent shift increases ceteris paribus host country welfare, since foreign profits are not part of host country welfare. Government revenues may even receive particular weight in government decision making either if corrupt governments are able to appropriate part of it, or if governments have difficulties in collecting taxes from national sources.

The self-interest of one group of countries to negotiate a multilateral agreement with the purpose of liberalizing FDI arises to avoid an indirect subsidy across countries. Due to incomplete information, MNEs rest their location decision on the perception of some average country type and lose from businesses in unexpectedly illiberal countries but gain from those in unexpectedly liberal ones. Hence, resources are transferred indirectly from countries that are unexpectedly liberal towards FDI to those that are not.

The protest of another group of countries against negotiation of the first one arises from the fear that the decision whether to join a multilateral investment agreement reveals information on the government type. A partial information revelation reduces the implicit subsidy and diverts FDI towards members of an agreement. ${ }^{10}$ Hence, an agreement exerts

\footnotetext{
${ }^{10}$ Our concern with a national political equilibrium in driving multilateral negotiations is motivated by concerns of close observers of the negotiations. For example, the WTO economist Drabek - otherwise strongly in favor of MAI - points out as one major disadvantage of MAI:

"Suppose first that a country makes the equity issue a top social priority. Suppose further that a deeper market opening (i.e. globalisation) increases income inequality. Should the country's government be concerned?... Or, suppose that a government has a policy of maintaining a fine social balance among different races or other social groups in order to maintain a social order and political stability. ... Suppose further that globalisation would disturb this fine balance. Again, should the government be concerned? The
} 
an information externality on countries because they are free to join or opt out.

A final modelling decision regards the definition of FDI. The classical approach views FDI as a flow of physical capital. The modern approach considers the activity of MNEs, where the nationality of corporate control is different from the nationality of a plant location. Typically, differences in control involve differences in technology both with respect to total factor productivity and factor intensities. FDI flows are then flows of technology. We will adhere to the modern approach. ${ }^{11}$

Summing up, we will set up a model where FDI is driven by relative factor endowments and political risk, and affects relative factor rewards which feeds back into political decision making.

\section{Model Set-up}

In broad terms, we describe a world economy with FDI and endogenous government policy in a multi-stage game. The timing is displayed in Figure 1. In a first period, the countries are determined that start negotiating a multilateral investment agreement (MAI). Then, a common rule of FDI regulation is bargained over. Next, all countries in the world make their choice of participation in MAI. Thereafter, MNEs locate to countries conditional on observing the MAI membership decision but without knowing government policies. Eventually, MAI member and non-member countries choose how liberal their investment regime will be subject to their choice of MAI participation. In the second period, firms have the possibility to re-locate in response to the revealed government regime. The model is solved by backward induction.

Insert Figure 1 about here.

Before discussing the political economy of multilateral investment agreements, we need to elaborate on how FDI affects host countries.

answer to both questions is in my view - yes, it should." (Drabek, 1998, p. 13)

${ }^{11}$ For surveys see Markusen (1995) and Markusen (2002). 


\subsection{Modelling FDI}

To keep the model as simple as possible, we refrain from many features of MNE models. For example, we define MNEs as one-plant firms with foreign ownership rather than multiplant firms. Other features of MNEs are kept. For example, MNEs have a superior technology compared to local firms. Moreover, MNEs are free to choose their location among many countries. Finally, MNEs operate with scale economies.

To be precise, we consider a world with a unit mass of countries indexed by i. Each country is endowed with some units of labor $L_{i}$ and capital $K_{i}$. We think of capital as internationally immobile resources such as human capital, land, or natural resources. An MNE operates with constant marginal cost. There are $A$ units of labor necessary to produce one additional unit of output, $A<1$. To start operation, overhead cost have to be born. For simplicity, one unit of a Cobb-Douglas composite of capital and labor is necessary, i.e. $1=k^{0.5} l^{0.5}$, where $k$ and $l$ are the plant-headquarter demand of an MNE of capital and labor in a host country, respectively. We will assume that all MNEs are symmetric and do not require therefore a firm index. The capital share is set to 0.5 only to obtain smooth analytical closed form solutions and to apply simple numerical solution methods. However, our results will not depend qualitatively on this choice.

Local firms do not have access to modern technology. We assume as in Murphy et al. (1989) that local firms, i.e. firms owned by nationals, employ a traditional CRS technology, where one unit of labor is transformed into one unit of output. Such a technology is available to anyone in all product markets without market entry or exit barriers.

Consumers are split into workers and rent owners. Only workers demand MNE products. Otherwise, consumers are in all countries identical. There is a unit mass of products, of which an endogenous fraction is supplied by MNEs. The utility function obeys the standard assumptions, all products enter symmetrically, there is no love of variety, and the demand elasticity is sufficiently large such that the monopoly price of all MNEs will be above one in equilibrium.

Trade cost are absent. Factors are intersectorally, but not internationally mobile. Wages are chosen to be the numeraire (in one country). We assume that there is no 
complete specialization. Hence, product prices in sectors without MNEs will be one due to international trade and wages will be one in all countries due to perfect competition. Product prices in sectors with MNEs will also be (marginally below) one, because MNEs will employ a limit pricing strategy. If they chose a price larger than one, local firms would enter and the MNE would forgo strictly positive profits. Since the monopoly price is larger than one by assumption, the MNE would also give up on profit opportunities if the product price was set strictly below one. As a result, whenever an MNE exists in a product market, it will serve the entire market. Local firms will only be present in markets where no MNE exists. While such a framework is rather unusual in international trade, it is a standard model of LDCs on which we focus. At the same time, it enormously simplifies the analysis, since prices and wages are quasi fixed exogenously. Changes in relative factor rewards are still possible since the capital rents are flexible and will differ across countries in equilibrium.

Finally, we assume risk neutrality of MNEs. Then, there is entry of MNEs in host countries until expected profits are zero. Ownership of MNEs is exogenously distributed across countries without further specification. Firm headquarters do not absorb any resources for simplicity. The superior technology of MNEs is obtained by chance rather than by resource absorbing $R \& D$ activity.

Turning to optimal MNE choices, the relative factor demand will obey $l_{i t Z}=$ $r_{i t Z} k_{i t Z}$, where $r_{i t Z}$ is the rental rate, $i$ the country index, $t$ the time period $(t=1,2)$, and we recall that there is a re-allocation of MNEs and production factors after announcement of the FDI regime in period 2. Moreover, the index $Z, Z \in\{N, I, O\}$, indicates whether we consider a world without a MAI $(N)$, or a country in a world with MAI that opts out of MAI $(O)$, or a country in a world with MAI that opts in $(I)$. Capital market clearing requires $\phi_{i t Z} \cdot k_{i t Z}=K_{i}$, where $\phi_{i t Z}$ is the mass of sectors with MNE firms in country $i$ - called FDI inflows for short. We abstract from the possibility that some firms with a superior technology may actually be owned by nationals. This is consistent with the model set-up, however, since the location choice of an individual firm is indeterminate by the assumption of symmetry of firms. If such a choice follows a random process, then the probability of locating in the country identical to the nationality of its owner is zero. 
The free entry condition of MNEs ensures that expected profits are zero:

$$
l_{i t Z}+r_{i t Z} \cdot k_{i t Z}=\left[1-\beta_{i Z}\right](1-A) Y
$$

where we recall that price and wage are one, $(1-A)$ is the profit mark-up, $Y$ demand for one MNE good, and $\beta_{i Z}$ incorporates a rate of rent extraction of countries from MNE operating profits that is time-invariant in accordance with Figure 1. We think of rent extraction as all kind of policy measures that are intended to reduce MNE profits. These may be both direct measures like taxation, fines, or expropriation and indirect measures like the requirement to engage in joint ventures with local partners, relaxation of intellectual property right protection, or red tape cost. We assume that rent extraction generates government revenue.

The equilibrium rental rate is found to be

$$
r_{i t Z}=\phi_{i t Z}^{2} K_{i}^{-2}
$$

Hence, FDI inflows exert upward pressure on rental rates. While this is not directly obvious from vertical FDI theory, it corresponds with empirical stylized facts. Quite important for the perception of politicians that negotiated the MAI in the late 90ies was the experience of Ireland in the early 90ies. This country was able to trigger a spectacular catch-up by an FDI promotion strategy including a generous tax break on MNE profits repatriated from Ireland. Barry and Bradley (1996) report that inward FDI was both human-capital and physical-capital intensive. At the same time, relative high-skilled wages and real-estate rental rates rose sharply with incoming FDI flows in line with our model. Similar relative factor price changes are found in Feenstra and Hanson (1997) for Mexico.

In period two, the rent extraction rate $\beta_{i Z}$ is known to the firm and the zero profit condition implies:

$$
\phi_{i 2 Z}=0.5 K_{i}\left[1-\beta_{i Z}\right] Y \equiv \phi\left(\beta_{i Z}\right) \text {. }
$$

FDI inflows depend on two country-specific factors - the capital endowment of a country 
$K_{i}$ and the rent extraction rate $\beta_{i Z}$. In a sense, FDI is resource-seeking in this model.

In period one, the firm does not know the rent extraction rate $\beta_{i Z}$. In a world without MAI, a risk neutral firm simply forms the unconditional expected value on it which we denote in slight misuse of standard notation by $E\left[\beta_{i N} \mid N\right]$. Instead, in a world with MAI, the firm exploits the information on the MAI membership decision $M \in\{I, O\}$ in forming a conditional expectation on $\beta_{i M}$ denoted by $E\left[\beta_{i M} \mid M\right]$. Then, the condition of zero expected profits allows to solve for FDI inflows in period 1 conditional on whether a country $i$ is member of MAI or not. Taken together, we have

$$
\phi_{i 1 Z}=0.5 K_{i}\left(1-E\left[\beta_{i Z} \mid Z\right]\right) Y
$$

for $Z \in\{N, I, O\}$. Solving for the rental rates in periods one and two finally from (2)-(4) yields:

$$
r_{i 2 Z}=0.25\left(1-\beta_{i Z}\right)^{2} Y^{2} \equiv r\left(\beta_{i Z}\right)
$$

and

$$
r_{i 1 Z}=0.25\left(1-E\left[\beta_{i Z} \mid Z\right]\right)^{2} Y^{2} \equiv r\left(E\left[\beta_{i Z} \mid Z\right]\right) .
$$

Since FDI inflows increase the capital rewards and the government can steer by choice of the FDI regime the FDI inflows, the degree of FDI liberalization appears as an indirect policy instrument to redistribute factor incomes within a country.

To close the model, we assume for simplicity that world demand for MNE goods stems only from workers. Workers symmetrically distribute their income towards a mass one of products (since all prices are one), whereof a fraction $\Phi_{t Z}$, which is equal to the aggregate of $\phi_{i t Z}$ over all countries, is produced by MNEs. Hence, demand that falls onto MNEs is just $Y=\int L_{i} d i$, where we recall that wages are one. This assumption serves to sharpen our results and to render analysis tractable. There won't be wrong conclusions drawn from our model as long as there is not expected a major increase of world income through the creation of MAI. This is plausible, since MNEs make up only a small part 
of economic activity even in highly developed countries. ${ }^{12}$ It is further assumed without loss of generality that $\Phi_{t Z}<1$. If it were not true, then there would be entry of new firms creating new products and the mass of products would increase above 1 . Since $Y$ is constant, and there is no love of variety, this remains without consequence for the model.

In the next section, we discuss what may determine the political equilibrium of factor income redistribution.

\subsection{Modelling a political equilibrium}

The rent extraction rate $\beta_{i Z}$ is determined by governments. We assume that a government of a country maximizes a country welfare term that is biased towards some interest group. Grossman and Helpman (1994) consider a lobbying model where specific factor-owners pay campaign contributions to the government to convince her to shape government policy in the lobby-groups' interest. Since wages are fixed by construction, we assume that capital owners are lobbying for policies that increase rental rates. (We will later discuss this assumption.) Such a set up can be written in reduced form as a maximization problem of the following government objective function $W_{i Z}\left(\chi, \beta_{i Z}\right)$ with respect to the rent extraction rate $\beta_{i Z}$ (see Grossman and Helpman, 1996, and Ethier, 1998) ${ }^{13}$ :

$$
\begin{aligned}
W_{i Z}\left(\chi, \beta_{i Z}\right)= & 2 L+\chi r_{i 1 Z} K_{i}+\chi r\left(\beta_{i Z}\right) K_{i} \\
& +u \beta_{i Z} Y \phi_{i 1 Z}+u \beta_{i Z} Y \phi\left(\beta_{i Z}\right) .
\end{aligned}
$$

\footnotetext{
${ }^{12}$ A related argument has been used in Krugman (2000) showing that international trade of the NorthSouth type makes up an almost negligible part of OECD GDP. This is even more so true of North-South FDI despite its growth. Exact numbers are hard to come by, but the following figure may give an idea of the magnitude of FDI activity. There are a mere 2.7 million employees of US affiliates in emerging market economies and LDCs in 1996 (UNCTAD, 1999, p. 450), which is quite small compared to the US labor force.

${ }^{13}$ A study that applies a lobbying framework on policy determinants of factor prices to a small open economy with internationally mobile factors is Facchini and Willmann (2005). However, a multilateral investment agreement is not discussed. Grossman and Helpman (1996) analyzes trade protection in a lobbying model in the presence of MNEs.
} 
The government objective function depends on factor incomes and on tax revenue in both periods. ${ }^{14}$ Importantly, factor income of a country rises with inflows of FDI. This provides an incentive to liberalize FDI. ${ }^{15}$

Since firms locate first, then governments choose rent extraction, and finally firms re-locate, there arises a time inconsistency problem. Because MNEs cannot evade higher rent extraction in the first period, this will create an upward bias in rent extraction when compared to the welfare-optimal one. This time inconsistency problem is standard in modelling political risk, as was pointed out in a previous section. ${ }^{16}$ Less standard is the lobbying term $\chi, \chi \geq 1$, that increases the weight of capital income in the government objective function and will bias the rent extraction rate downward.

Strictly speaking, the time inconsistency problem does not involve risk, since the optimal government behavior can be foreseen. We introduce political risk by assuming that MNEs have incomplete knowledge on the lobbying term $\chi$ which is assumed to be a random variable. To simplify the analysis, we assume that $\chi$ is uniformly distributed on the interval $[1, \bar{\chi}]$, where $\bar{\chi}$ is some upper bound such that $1<2 u<\bar{\chi}<\infty$. The second inequality serves only to avoid cumbersome notation but does not substantially affect results. We distinguish in our notation $\chi$ for the random variable and $\chi_{i}$ for its realization of country $i$.

Political risk arises thus from the unpredictability of government change when there are different types which are more or less prone to FDI liberalization. If $\chi=1$, then equation (7) represents country welfare when taking into consideration that profits are zero in equilibrium.

\footnotetext{
${ }^{14}$ We ignore discounting for simplicity.

${ }^{15}$ This result is in contrast to Brecher and Diaz-Alejandro (1977) which shows that capital inflows may reduce host country welfare in the presence of a small tariff. The difference in effects arises from the different definitions of FDI. While Brecher and Diaz-Alejandro (1977) considers FDI as an inflow of physical capital, we consider FDI as an inflow of technology that rises the demand for capital rather than its supply. Our result can easily be shown to generalize to general functional forms and different sector settings. It does not hinge on fixing the wage at one.

${ }^{16}$ Janeba (2002) has pointed out that there must be a mutual time inconsistency problem. Countries cannot commit to certain policies and firms cannot commit to stay in a country. Otherwise, an upfront subsidy would solve the time inconsistency problem and no international agreement was necessary. An upfront subsidy will not be an equilibrium, if a firm cannot commit to invest after receiving the subsidy. We exclude an upfront-subsidy solution to the time-inconsistency problem exogenously.
} 
While it is widely acknowledged that there are host country benefits from FDI, LDCs claim, however, control over foreign investors. For example, Ganesan, a former Indian commerce secretary to the government, points out that it " ... becomes necessary for developing countries to employ an appropriate mix of incentives and performance requirements for FDI to achieve specific developmental objectives." (Ganesan, 1998, p. 5)

To build into the model a specific LDC development objective with respect to FDI, we allow for an underprovision of public goods that is typical for many developing countries. Such an underprovision may arise from the lack of an efficient tax authority, for example, in countries with corrupt bureaucracies. Moreover, there are scale economies of control to avoid tax evasions. Small local firms may not be taxed because fixed control cost are larger than the tax revenue from a firm if production is small. ${ }^{17}$ For these reasons, an LDC government may have a budget constraint on public goods such that marginal utility of public goods is larger than of private goods $(u>1)$. For simplicity, we assume the marginal utility of public goods to be a constant mark-up over private marginal utility.

The optimal choice of the rent extraction rate in a world without MAI $\beta_{i N}$ is found by inserting equation (4): ${ }^{18}$

$$
\beta_{i N}=\left\{\begin{array}{cl}
\beta\left(\chi, E\left[\beta_{i N} \mid N\right]\right) & \text { if } \chi<\chi_{N u} \\
0 & \text { else }
\end{array}\right.
$$

where

$$
\beta\left(\chi, E\left[\beta_{i N} \mid N\right]\right) \equiv \frac{\chi-u}{\chi-2 u}-\frac{u\left(1-E\left[\beta_{i N} \mid N\right]\right)}{\chi-2 u}
$$

and

$$
\chi_{N u} \equiv u\left(2-E\left[\beta_{i N} \mid N\right]\right)
$$

Interestingly, the optimal rent extraction rate depends only on the country characteristic $\chi$ but not on endowment differences.

There is a simple interpretation of equation (9). Without any distortions, the

\footnotetext{
${ }^{17}$ See Burgess and Stern (1993) for this reasoning, p. 775 and p. 799, and many related issues.

${ }^{18}$ Consistent with our argument on a lack of government financing through local taxes, we assume that MNE subsidies are not feasible.
} 
country-welfare optimum is no rent extraction, since factor allocation is efficient. If there is a larger marginal utility of public than of private goods, then a country is willing to accept lower factor incomes in exchange for a larger government revenue and better public good provision. Hence, some strictly positive rent extraction is optimal. Indeed, the optimal value to country-welfare optimization is $(1-u) /(1-2 u) \geq 0$. Its deviation from the term $[\chi-u] /[\chi-2 u]$ in equation (9) represents the bias through lobbying. Since the capital lobbyists favor lower rent extraction to promote FDI and push up rental rates, the second bias is negative. Instead, the second term on the right-hand side can be shown to be positive and represents the time-inconsistency bias of $\beta_{i N}$ from the optimum of the government.

Lemma 1 The function $\beta\left(\chi, E\left[\beta_{i N} \mid N\right]\right)$ is monotonically decreasing in $\chi$ on the range $1 \leq \chi \leq \chi_{N u}$ and $0 \leq \beta_{i N}<1$ for all countries $i$.

Proof: See Appendix 1.

We will need these properties of $\beta_{i N}$ to analyze further optimal firm behavior and the MAI entry choice of countries.

\subsection{Modelling MAI}

Before we continue the analysis, we define MAI. There are many provisions in the negotiated MAI agreement in the various versions from 1995 to 1998. However, economically relevant seems to be how the various provisions restrict the action space of governments to extract rents from MNEs. ${ }^{19}$ In particular, provisions like the most favored nation clause and the national treatment clause reduce incentives of governments to extract rents, since agents with the weakest political support (i.e. foreigners without votes in national parliaments) are protected by those with the strongest (i.e. national firms or foreign firms supported by powerful governments). Moreover, there were provisions in the proposal that guaranteed liberalization of FDI in a broad sense.

\footnotetext{
${ }^{19} \mathrm{~A}$ similar formalization of FDI provisions in NAFTA is found in Fernandez-Arias and Spiegel (1997).
} 
For the sake of concreteness, we assume that MAI members agree on a common standard of maximum rent extraction $B$ such that

$$
\beta_{i I} \leq B
$$

Such an asymmetric rule that constrains some countries but not others is a likely outcome if an exclusive club negotiates it and is bound to agree unanimously among club members. In fact, it is easiest to agree unanimously to a rule that constrains only countries that do not participate in the negotiation. There may still be a benefit to the negotiators from this rule if the MAI causes a positive externality to the negotiators (through investment diversion).

We assume that such a rule is self-enforcing without providing a formal argument. Self-enforcement may follow from the DSP that was part of the MAI provisions and may act in a similar way as the one for the WTO. ${ }^{20}$ Alternatively, the self-enforcement may arise from combined trade and investment accords. See Fernandez-Arias and Spiegel (1997) for a regional trade and investment agreement in a three-country world where a North-South agreement is self-enforcing, because the South punishes by taxing FDI and the North punishes by levying a tariff on imports in a model with outsourcing.

In practice, the MAI draft of 1998 included an even stronger mechanism that ensures enforceability. The MAI was planned to become legally binding by incorporating it into national law and opening the doors of national courts to MNEs to sue governments for their policies and regulatory takings that conflict with the MAI provisions. ${ }^{21}$

\subsection{Defining equilibrium of subgame with exogenous MAI rule}

We are now ready to define a subgame perfect equilibrium of the stages over MAI membership choice, optimal rent extraction by governments, and firm location in both periods. Such an equilibrium will be given if (i) MNEs enter or exit a country until the zero-

\footnotetext{
${ }^{20}$ Bagwell and Staiger (1999) shows how the dispute settlement procedure of GATT is self-enforcing.

${ }^{21}$ Ethier (1998) in a theory of regionalism takes the enforcement issue also as exogenous and provides additional reasons that apply in our case, too.
} 
expected-profit condition holds conditional on knowing the government type $\chi$ in period 2, (ii) countries maximize their objective function value conditional on their membership choice and on expectation formation of MNEs, (iii) MNEs enter or exit a country until the zero-expected-profit condition holds where rational expectations are formed on the rent extraction rate conditional on a countries' membership decision in period 1, and (iv) countries optimize their objective function when deciding on MAI membership given other countries actions, firm expectation formation, and their own policy of rent extraction after membership choice. Moreover, we define a partial MAI equilibrium of this subgame at a given MAI rule (10) as an equilibrium where some countries decide to enter MAI and others opt out. Instead, a complete MAI is an equilibrium where all countries join MAI. We are mainly interested in the analysis of partial MAI.

Optimal firm behavior is already discussed in section 3.1 apart from MNEs' expectation formation. To characterize expectation formation, however, the optimal government choices have to be analyzed. The countries that opt into MAI choose the optimal rent extraction rate in analogy to the case without MAI in equation (8) by $\beta_{i I}=\beta\left(\chi, E\left[\beta_{i I} \mid I\right]\right)$ whenever the MAI rule $(10)$ is not binding $\left(\beta\left(\chi, E\left[\beta_{i I} \mid I\right]\right) \leq B\right)$. The case, when the rule is binding will be discussed in section 3.6. The optimal rent extraction rate choice of a country $i$ when opting out is given by $\beta_{i O}=\beta\left(\chi, E\left[\beta_{i O} \mid O\right]\right)$. The expectation on rent extraction depends on how countries decide to enter MAI or opt out once a particular MAI exists. This is analyzed in the next section.

\subsection{Self-selection of countries}

The decision to enter a MAI of given strictness $B$ is made based on the government objective function under the two alternative choices. First, the government objective function when entering MAI shall be denoted $W_{i I}\left(\chi, \beta_{i I}\right)$ and the objective function when opting out by $W_{i O}\left(\chi, \beta_{i O}\right)$. By the Nash-conjecture, opponent countries actions are taken as given and thus $\phi_{i 1 Z}$ is exogenous to the MAI membership choice. Under this condition, we find a self-sorting order in Lemma 2.

Lemma 2 A country $i$ will prefer to opt out (in) if $\chi_{i}<\chi^{*}\left(\chi_{i}>\chi^{*}\right)$, where $\chi^{*}, \chi^{*}>1$, 
is a threshold value such that $W_{i I}\left(\chi^{*}, \beta_{i I}\right)=W_{i O}\left(\chi^{*}, \beta_{i O}\right)$. Formally, $W_{i I}\left(\chi_{i}, \beta_{i I}\right) \lessgtr$ $W_{i O}\left(\chi_{i}, \beta_{i O}\right)$ if and only if $\chi_{i} \lessgtr \chi^{*}$.

Proof: See Appendix 2.

Intuitively, each country faces a trade-off. When increasing the rent extraction rate, the government revenue increases and FDI inflows decrease which reduces total factor income. The larger is the weight $\chi_{i}$ the smaller is chosen a $\beta_{i Z}$ to find the optimal trade-

off. When comparing the government objective functions of two countries $i$ and $i^{\prime}$ with marginally different lobbying terms $\chi_{i}$ and $\chi_{i^{\prime}}$ with $\chi_{i}>\chi_{i^{\prime}}$, then $i$ will choose a marginally lower rent extraction rate $\beta$. Since the $\beta$-choice of both countries is optimal for them, the impact of changing $\beta$ optimally when changing $\chi$ has only a second-order effect on the objective function by the envelope theorem. The only remaining first-order effect is the direct effect of a change in the valuation $\chi$ of capital income. Capital income in MAI is, however, larger than outside MAI, because rent extraction inside is restricted while it is not outside. Hence, MNEs expect lower rent extraction from members, and devote more FDI there which causes a country to have a higher rental rate when inside MAI than when outside. Finally, the larger rental income benefits more those countries with larger valuation of capital income. Hence, MAI membership is the more desired the larger is the valuation term $\chi$.

We can show that this mechanism generalizes to any usual functional forms and different ways of modelling FDI as long as MAI consists of a maximum rent extraction rule for members that is credible. Yet, this self-sorting order will be a crucial mechanics for our model.

\subsection{Forming expectations on rent extraction}

When deciding in period 1 on the MNE location, firms observe the decision of countries to join MAI or opt out. Hence, they form expectations on the rent extraction rate conditional on this information.

Before we can form expectations, we need to characterize how countries $i$ determine their rent extraction rate and membership decision in the presence of a MAI rule (10) when 
it is binding $\left(\beta\left(\chi_{i}, E\left[\beta_{i I} \mid I\right]\right)>B\right)$. For this purpose, we define a threshold $\tilde{\chi}$ such that $\beta\left(\tilde{\chi}, E\left[\beta_{i I} \mid I\right]\right) \equiv B$, and obtain the next Lemma.

Lemma 3 (i) There is a group of countries $i^{*}$ with $\chi^{*}<\chi_{i^{*}}<\tilde{\chi}$ such that these countries enter MAI, although the MAI rule (10) is binding if a $\chi^{*}, \chi^{*}>1$, exists such that $W_{i I}\left(\chi^{*}, \beta_{i I}\right)=W_{i O}\left(\chi^{*}, \beta_{i O}\right)$.

(ii) For a country $i^{*}$ with a corresponding $\chi_{i^{*}}=\chi^{*}, \chi^{*}>1$, such that $W_{i I}\left(\chi^{*}, \beta_{i I}\right)=$ $W_{i O}\left(\chi^{*}, \beta_{i O}\right)$, there must be $\beta\left(\chi^{*}, E\left[\beta_{i O} \mid O\right]\right)>B$.

Proof: See Appendix 3.

Summing up the insights on the optimal rent extraction rate from Lemmas 2 and 3 , we can describe the country choice of the rent extraction rate $\beta_{i M}$ in a world with MAI under the assumption that country $i^{*}$ with lobbying parameter $\chi_{i^{*}}=\chi^{*}$ is indifferent of its choice to join MAI or opt out as:

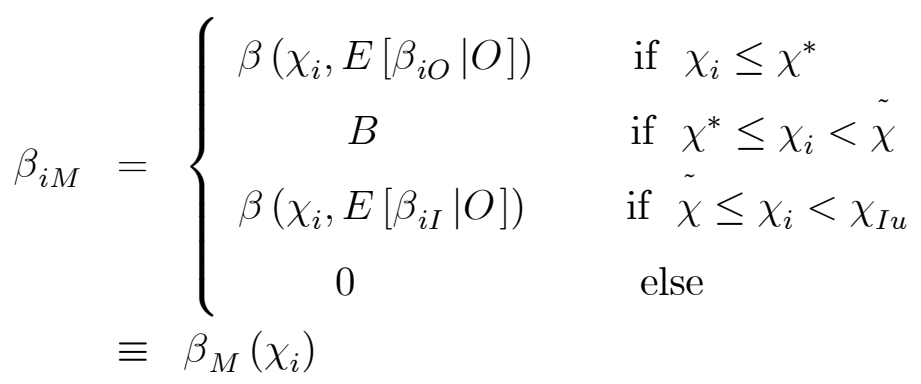

where $\chi_{I u}=u\left(2-E\left[\beta_{i I} \mid I\right]\right)$. First of all, we observe that $\beta_{i M}$ does neither depend on world income $Y$ nor on any country factor endowments. Moreover, it is only through $\chi_{i}$ depending on $i$. It is straight forward analogous to Lemma 1 that

$$
\frac{\partial \beta_{M}(\chi)}{\partial \chi} \leq 0 \quad \text { for } \chi \neq \chi^{*}
$$

The larger is the weight of the government objective function on rental income the less inclined is this government to extract rents from foreign firms, reduce the FDI inflows, and suffer from lower capital income. 
We assume that there exists a country $i^{*}$ with a corresponding $\chi_{i^{*}}=\chi^{*}$ such that this country is indifferent of entering MAI or opting out. Then, the conditional expectation of the rent extraction rate $\beta$ dependent on the MAI decision is given as follows:

$$
E\left[\beta_{i O} \mid O\right]=\frac{\int_{1}^{\chi^{*}} \beta_{M}(\chi) d \chi}{\chi^{*}-1},
$$

where we apply Lemma 2, the assumption on a uniform distribution of the lobbying term $\chi$, and equation (11). When plugging (8) into equation (13) and developing the integral we obtain a convenient closed form solution:

$$
E\left[\beta_{i O} \mid O\right]=\frac{-u \ln \left(\frac{2 u-\chi^{*}}{2 u-1}\right)}{\chi^{*}-1-u \ln \left(\frac{2 u-\chi^{*}}{2 u-1}\right)} .
$$

The expected value $E\left[\beta_{i O} \mid O\right]$ depends only on one endogenous variable - the partition of countries $\chi^{*}$ - and must be falling in it, because the expansion of $\chi^{*}$ leads to an addition of countries outside MAI with a rent extraction rate lower than the average among outsiders.

The expected value of the rent extraction rate inside MAI is a bit more complicated to determine. It is given from Lemma 2 and Lemma 3 as:

$$
E\left[\beta_{i I} \mid I\right]=\frac{\int_{\tilde{\chi}}^{\chi_{u}} \beta_{M}(\chi) d \chi+\left[\tilde{\chi}-\chi^{*}\right] B}{\bar{\chi}-\chi^{*}} .
$$

Also in this case we can obtain a closed form solution after tedious calculations

$$
E\left[\beta_{i I} \mid I\right]=\frac{\left(2 u-\chi^{*}\right) B}{\bar{\chi}-\chi^{*}-u \ln (1-B)} .
$$

Accordingly, the expected value $E\left[\beta_{i I} \mid I\right]$ depends only on the endogenous variable $\chi^{*}$, and falls in it for the same reason as before.

Finally, we obtain the optimal choice of the rent extraction rate when the indifferent country $i^{*}$ is opting out:

$$
\beta_{i^{*} O}=1-u \frac{E\left[\beta_{i O} \mid O\right]}{2 u-\chi^{*}} \equiv \beta_{O}\left(\chi^{*}\right)
$$

Also this rent extraction rate depends only on one endogenous variable $\chi^{*}$. Concerning 
the exogenous variables, the expected values of the rent extraction rates depend on the marginal utility of public goods $u$, the strictness of MAI $B$, and the distribution parameter $\bar{\chi}$. They do not depend on world income or factor endowments.

From equations (11), (12), (13) and (15) we can infer the following order of rent extraction rates

$$
E\left[\beta_{i I} \mid I\right] \leq B<\beta_{O}\left(\chi^{*}\right) \leq E\left[\beta_{i O} \mid O\right]
$$

expected by MNEs for all possible interior values of $\chi^{*}$.

Finally, we find from (4), and (18) that

$$
\phi_{i 1 I}>\phi_{i 1 N}>\phi_{i 1 O}
$$

for all possible interior values of $\chi^{*}$. Inequality (19) expresses an investment diversion channel in the model. Since countries that join MAI are self-selected to be the ones that extract the least rents from MNEs, MAI membership reveals information to the MNEs and increases FDI inflows relative to both a world without MAI and to a situation when a country opts out. Likewise, when opting out, there is a signal of bad quality to MNEs, and FDI inflows are lower both relative to a situation when joining MAI or when there does not exist a MAI. Equation (11) reveals then that MAI countries get an extra incentive to extract rents, since a larger rent-extraction base enlarges the time inconsistency problem. Conversely, outsiders have a reduced incentive to extract rents, since the rent-extraction base is diminished and the time inconsistency problem reduced.

We can summarize the discussion in this section by drawing a graph of the chosen rent extraction rate in dependence of the underlying lobbying parameter $\chi_{i}$ (formalized in equation (11)).

Insert Figure 2 about here

Figure 2 describes with the thick line the rent extraction rate in a world with partial MAI. Under the assumption that a country $i^{*}$ exists with $\chi_{i^{*}}=\chi^{*}$ such that this country is 
indifferent, a kink and a jump occur. The jump is explained by Lemma 3. Since, when opting out of MAI, FDI inflows are reduced due to the disadvantageous signal of nonmembership, the rent extraction rate must be substantially higher than the maximum standard to compensate with higher revenues both for the loss in capital income and the reduction in the rent extraction base. The thin line, instead, depicts the rent extraction rate that would have prevailed in a world without MAI (formalized in equation (8)).

\subsection{Characterizing equilibrium for a given MAI}

Next, we characterize whether a partial MAI exists. A country $i$ is indifferent on the MAI membership decision if $W_{i I}\left(\chi^{*}, \beta_{i I}\right)$ equals $W_{i O}\left(\chi^{*}, \beta_{i O}\right)$. We can write this indifference condition as follows:

$$
\begin{aligned}
\tilde{W}\left(\chi^{*}\right) \equiv & w\left(E\left[\beta_{i O} \mid O\right], \beta_{O}\left(\chi^{*}\right), \chi^{*}\right)+w\left(\beta_{O}\left(\chi^{*}\right), \beta_{O}\left(\chi^{*}\right), \chi^{*}\right) \\
& -w\left(E\left[\beta_{i I} \mid I\right], B, \chi^{*}\right)-w\left(B, B, \chi^{*}\right) \\
= & 0,
\end{aligned}
$$

where $w(x, y, \chi) \equiv 0.25 \chi(1-x)^{2}+0.5 u(1-x) y$. The function $w(x, y, \chi)$ is the government objective value in a regime and a year of a country with a lobbying parameter $\chi$, a government choice of the rent extraction rate $y$, and a given expectation of MNEs on the rent extraction rate $x$. Interestingly, when expectations are correct $(x=y)$, the function has a peak in $x$ for a given $\chi$ at $(u-\chi) /(2 u-\chi)$. Only if $u>1$, the peak will be in the positive range and the desired rent extraction rate is positive. Otherwise, a rent extraction rate of zero is optimal for any indifferent country $i^{*}$. If $\chi=1$, the function $w(x, y, \chi)$ captures country welfare in a period.

Equation (20) is an implicit function of one endogenous variable $\chi^{*}$, because $E\left[\beta_{i O} \mid O\right]$, and $E\left[\beta_{i I} \mid I\right]$ depend according to (14) and (16) on no other endogenous variable than $\chi^{*}$. All other endogenous variables of the subgame can be solved for, once a $\chi^{*}$ exists and is known. 
Importantly, the indifference condition is homogeneous of degree zero in both world income and country factor endowments. Hence, the indifference function $W\left(\chi^{*}\right)$ does not depend on a country index $i$. Henceforth, the country index i can be dropped and country differences are fully accounted for by keeping track of $\chi$. This property hinges on the assumption of a Cobb-Douglas functional form of the fixed cost component of MNEs. It does not hinge on the preference assumption that only workers consume industrial mass products $\left(Y=\int L_{i} d i\right)$. Only the strictness of the MAI participation rule $B$, the distortion from the underprovision of public goods $u$, and properties of the distribution function of the pressure group distortion term $\bar{\chi}$ matter for the equilibrium.

Proposition 1 There exists a subgame perfect Nash equilibrium where all countries with $\chi_{i}>\chi^{*}$ join and all countries with $\chi_{i}<\chi^{*}$ opt out of $M A I$ for some value $\chi^{*}, 1<\chi^{*}<\bar{\chi}$, if

$$
2 w\left(\frac{2 u-1}{3 u-1}, \frac{2 u-1}{3 u-1}, 1\right)-w(B, B, 1)-w\left(\frac{(2 u-1) B}{\bar{\chi}-1+\ln (1-B)}, B, 1\right)>0
$$

\section{Proof: See appendix 4.}

We are unable to prove uniqueness of the equilibrium, however it depends on the indifference condition (20) to have a unique solution. A sufficient condition would be that this function is monotonic in its argument. Hence, we give the first derivative of the indifference condition:

$$
\begin{aligned}
\frac{\partial \tilde{W}\left(\chi^{*}\right)}{\partial \chi^{*}}= & \frac{\partial w}{\partial E\left[\beta_{i O} \mid O\right]} \frac{\partial E\left[\beta_{i O} \mid O\right]}{\partial \chi^{*}}-\frac{\partial w}{\partial E\left[\beta_{i I} \mid I\right]} \frac{\partial E\left[\beta_{i I} \mid I\right]}{\partial \chi^{*}} \\
& +r\left(E\left[\beta_{i O} \mid O\right]\right)+r\left(\beta_{O}\left(\chi^{*}\right)\right)-r\left(E\left[\beta_{i O} \mid O\right]\right)-r(B) .
\end{aligned}
$$

The terms in the first line of (22) display the impact that the membership decision of the indifferent country has on the expected rent extraction of MAI member countries and outsiders which in turn influences FDI inflows, the rent extraction base and the rental 
rates. These two terms together are negative. The terms in the second line are the direct valuation effect from a larger lobbying term $\chi$ on the welfare function. It can be readily seen from (5), (6), and (18) that these terms together are positive, since rental rates are lower outside MAI and this affects adversely more countries with larger lobbying term $\chi$. Intuitively, the effects in the second line must dominate, because the ones in the first line are only of a second-order magnitude, since an individual countries' decision cannot have a first-order effect on an aggregate variable such as the expected rent extraction rate over a continuum of countries. In fact, as the number of countries goes to infinity, these terms will vanish. However, a formal proof is difficult and we can show it only for the special case $B=0$ (not reported).

Instead, we resort to a numerical simulation of condition (20) that is an implicit function of one endogenous variable and merely three parameters. As expected, we always found a unique interior solution whenever condition (21) applied. ${ }^{22}$

Since the condition (21) in Proposition 1 is a bit hard to understand economically, we provide two corollaries with simple intuitions.

Corollary 1: (i) If $u=1$, then the only equilibrium is one where all countries join MAI.

Proof: See Appendix 5.

Corollary 1 has a simple economic meaning. If there is no underprovision of public goods $(u=1)$, then the only Pareto-optimal allocation of factors is the one without government intervention despite monopoly power in goods markets. The only two distortions in the economy left are the time inconsistency problem and the lobbying distortion. The time inconsistency problem is fully solved by the MAI rule, and the lobbying distortion is towards zero, i.e. the free market solution. Hence, all countries decide to join MAI and the MAI preferred by all countries is the strictest one possible, i.e. $B=0$. Since there were LDCs objecting to MAI negotiations, the scenario without underprovision of public goods does not fit this empirical observation and we continue to analyze the case $u>1$.

\footnotetext{
${ }^{22}$ We did one robustness check and numerically simulated a model where we replace the assumption of a uniform distribution of the lobbying parameter $\chi$ by the assumption of a symmetric single-peaked distribution. Also in this case, we obtained a unique equilibrium in all simulations.
} 
We note, however, that developed countries are much more likely to support MAI, because they are likely to have a less severe problem of an underprovision of public goods if one at all.

Another benchmark on the condition (21) is found with respect to the strictness of MAI $B$. We define a particular benchmark of B such that

$$
B^{*}=\frac{u-1}{2 u-1}
$$

and characterize a MAI when such a benchmark happens to be negotiated.

Corollary 2: If $B=B^{*}$, then the only equilibrium is one where all countries join MAI.

Proof: See appendix 6.

The intuition of Corollary 2 is also straight forward. The benchmark $B^{*}$ is the value of the rent extraction rate that is chosen by a social planner. Since the lobbying distortion pushes the desired rent extraction rate below $B^{*}$, the time inconsistency distortion alone causes a rent extraction rate above $B^{*}$. However, MAI rule $B^{*}$ provides to all countries a commitment device to solve the time inconsistency problem by joining MAI at no cost. Hence, opting out of MAI makes no longer sense. Overall, a weak MAI (large $B$ ) is not sharply binding and every country joins MAI to avoid losses from signalling high rent extraction rates once deciding to stay out.

Proposition 2 Governments of all countries that decide not to join MAI lose compared to a world without MAI, governments of all countries with $\chi_{i}>\tilde{\chi}$ gain. At least some governments of countries that join MAI with $\chi_{i}$ such that $\chi^{*}>\chi_{i}>\tilde{\chi}$ lose.

Proof: See appendix 7.

Proposition 2 compares the incentives of governments to protest against MAI negotiations. Every country that expects an outcome of the negotiation that will make it preferable not to join will object negotiation. This proposition can explain why some countries object other countries to negotiate a MAI even though they are neither forced 
into nor excluded from membership. A partial MAI, i.e. a MAI where some countries join and others opt out, exerts a negative information externality on non-members which signal that they are inclined to extract large rents from MNEs. The resulting investment diversion harms countries that do not join. It need to be kept in mind, however, that a loss for a government does not necessarily imply a welfare loss of the country, since government objectives are distorted by lobbying groups.

Proposition 2 can explain the protest storm of some LDCs against the negotiation of MAI by the club of the OECD countries, although they were both free to opt in or out. According to our explanation, they were fearing the information externality that may arise from the decision to opt out. The protest comes from governments that are ex post but not ex ante contra free-market spirited. Again, a quote by the former Commerce Secretary to Government of India supports this model feature. As a principal reason against MAI is given the following argument: "Selective and judicious government intervention is therefore widely considered necessary to support or protect domestic industry and technology creation ... Adequate freedom and flexibility to pursue their own policies towards FDI and foreign technology is therefore regarded by developing countries as a matter of fundamental importance ..." (Ganesan, 1998, p. 5)

\subsection{Negotiating MAI}

In this section, we turn to the stage when MAI is negotiated. We assume that there exists a club $\mathrm{C}$ of a countable number of countries that starts exclusively negotiating an agreement. In particular, this group chooses the threshold $B$. The club is assumed to have more favorable political-risk characteristics than the world as a whole.

All countries are then free to opt in or out after the agreement is written. We assume also that MAI takes the form of a rule $\beta \leq B$. Then the strictness of MAI, i.e. the threshold value $B$ can be found from a simple Nash bargaining solution where the Nash product is defined as

$$
\prod_{c \in C}\left[W_{c I}\left(\chi_{c}, \beta_{i M}, B\right)-W_{c N}\left(\chi_{c}, \beta_{i M}\right)\right]^{\frac{1}{|C|}}
$$


$|C|$ is the number of group members, and the government objective function of successful negotiation $W_{c I}\left(\chi_{c}, \beta_{i M}, B\right)$ obtains an additional argument $B$, since the strictness of MAI is now allowed to vary. In addition applies the participation constraint due to the assumption of unanimity among negotiators

$$
\left[W_{c I}\left(\chi_{c}, \beta_{i M}, B\right)-W_{c N}\left(\chi_{c}, \beta_{i M}\right)\right] \geq 0
$$

for all countries $c \in C$. Denote with $\chi_{s}$ the country with the smallest weight on capital income in the negotiation group C, i.e. $\chi_{s}=\min _{c \in C}\left\{\chi_{c}\right\}$. Likewise, we denote the country with the largest weight $\chi_{l}$, i.e. $\chi_{l}=\max _{c \in C}\left\{\chi_{c}\right\}$ Then the constraint (25) is not binding for any country unless it is binding for country $\chi_{s}$, since $\chi_{s}$ is the country that is first hit by a welfare loss according to Proposition 2 when the agreement gets too strict.

When maximizing the Nash product (24) with respect to MAI strictness B under the participation constraint (25), one obtains the following first order condition ${ }^{23}$

$$
\sum_{c \in C} \frac{\partial W_{c I}\left(\chi_{c}, \beta_{i M}, B\right)}{\partial B} \frac{1}{W_{c I}\left(\chi_{c}, \beta_{i M}, B\right)-W_{c N}\left(\chi_{c}, \beta_{i M}\right)}=0
$$

The negotiated strictness of the agreement is a weighted average over the individually optimal choices given by the first oder condition $\frac{\partial W_{c I}\left(\chi_{c}, \beta_{i M}, B\right)}{\partial B}=0$ the solution of which is denoted by $B(c)$. The first order condition (26) implies that the participation constraint (25) is never binding. As soon as B gets too strict for country $\chi_{s}$ it obtains an infinite weighting factor on its own first-order condition which ensures that B does not deviate too much from its own preferred choice. Hence, there must always exist a solution to the first order condition (26) such that the negotiated strictness B is between the one desired by the club member with the largest weight and the one with the lowest weight, i.e. $B(l)<B<B(s)$. Finally, $\mathrm{B}$ is unique, because the function $W_{c I}\left(\chi_{c}, \beta_{i M}, B\right)$ is single-peaked.

We collect the results in the following proposition.

Proposition 3 There exists a unique mapping of a club with a member set $C$ and an

\footnotetext{
${ }^{23}$ We assume that the optimization problem is well-behaved.
} 
agreement threshold $B, B=B(C)$. The strictness of this agreement is strictly bounded by the minimum and maximum of the individually optimal choices, i.e. $B(l)<B(C)<$ $B(s)$.

Proposition 3 is useful to characterize the equilibrium of the entire game.

\subsection{Prevalence of Bilateral Investment Agreements}

We turn now to the last stage of the game when many different groups can potentially negotiate agreements. It turns out that the negotiation result of an exogenously given heterogeneous group is not yielding a stable outcome. Not only is there protest against an agreement from some outsiders that obviously lose from the negotiation according to Proposition 2. There is also a disinterest of some countries within the negotiation group that find the negotiated contract too weak. This incentive leads to the next proposition.

Proposition 4 (i) To any negotiation group of countries $C$ that is heterogeneous in the lobbying parameter $\chi$, there exists a strict sub-group of $C$ that prefers a MAI negotiated within the sub-group.

(ii) If any pair of two countries has the commitment technology to form an investment agreement, then the only subgame perfect equilibrium is one where each country negotiates agreements together with countries of the same type $\chi$.

(iii) The negotiation outcome will be

$$
B(\chi)=\max \left[\frac{u-\chi}{2 u-\chi}, 0\right] .
$$

Proof: See appendix 8.

The intuition behind this proposition is simple. Consider again the country with the largest lobbying term $\chi_{l}$ in the negotiation group $C$. By forming a MAI which is stricter than the average over all members, this country can reveal more information on its type and thereby attract additional FDI without constraining its rent extraction rate choice, since country $\chi_{l}$ 's optimal choice of the constraint $B$ is a strictly lower value than the one negotiated by the large group. Hence, the most liberal country of a group has 
always an incentive to form a sub-group and to negotiate a stricter MAI. If every country does that, then there will result a world where there is an investment agreement for each type $\chi$ (BIT regime). ${ }^{24}$

This theoretical result matches quite well with two empirical observations: Firstly, after the group of negotiating countries was enlarged to include 8 LDCs on top of the OECD member countries to alleviate the protest storm of LDCs and NGOs, the latest versions of the agreement appeared full of exemptions of FDI liberalization, while the first versions were attempting a very general liberalization of FDI. When this contract suggestion was so weak that it was no longer binding for most countries, the main FDI source countries lost interest in it. This reasoning for the failure of MAI is found in Hoekman and Saggi (2000, p. 185): "In the end, OECD countries were only able to agree on a package that was less far-reaching than what is often found in the bilateral investment agreements between high-income and developing countries ..., reducing the interest of the business community to push for the agreement."

Our model mechanics was also anticipated in Drabek (1998, p. 9): ".. commitments negotiated by like-minded governments are often 'stronger' and deeper than those achievable at the multilateral level." [emphasis added]

Secondly, while a multilateral agreement failed in 1998, there was a spread of BITs at varying strictness throughout the 90ies. The number of BITs quadrupled during the 90ies to well above 1600 in the year $1998^{25}$. Not only are there many bilateral agreements, but also agreements of smaller groups of countries. ${ }^{26}$ This phenomenon has been termed the "new regionalism" (Ethier, 1998).

While the BIT regime is the one that is preferred by any government, it is not world-welfare maximizing, since government objectives are distorted by lobbying. We turn next to a MAI that is world-welfare improving compared to a BIT regime.

\footnotetext{
${ }^{24}$ Our model does not fully account for all features of typical BITs and regional agreements. For example, we ignore the trade part of regional agreements. As has been shown by Fernandez-Arias and Spiegel (1997), the trade part may be important to secure credibility of the commitment mechanism of an investment agreement which is taken as exogenous in our model.

${ }^{25}$ See UNCTAD (1998), figure III.3, p. 83.

${ }^{26}$ Regional arrangements across many countries would emerge in our model if not all pairs of countries have a commitment technology available. For example, it may be necessary to have a "natural contract enforcer" (Ethier, 1998) part of the agreement.
} 


\section{A World-Welfare-Superior MAI-Design}

In this section we suggest a MAI design that is welfare-superior compared to a regime of BITs, although we do not provide an optimal mechanism. Such a world-welfare-superior agreement can be designed as follows.

Proposition 5 Suppose an agreement exists such that

$$
\beta_{i I} \leq \frac{u-1}{2 u-1} \equiv B^{*}
$$

for all members, and bilateral agreements outside this arrangement are excluded, then this arrangement is strictly world-welfare superior compared to a regime with BITs.

Proof: See appendix 9 .

Again there is a simple intuition behind this result. First note that all countries join MAI under rule (28), as was found in Corollary 2. Then, the chosen rent extraction rate of any country $i$ if strictly positive is

$$
\beta_{i I}=\max \left[\frac{u-\chi_{i}}{2 u-\chi_{i}}+\frac{u\left(1-E\left[\beta_{i I} \mid I\right]\right)}{\left[2 u-\chi_{i}\right]}, B^{*}\right]
$$

which is between the one that maximizes the government-objective function, i.e. $\frac{u-\chi_{i}}{2 u-\chi_{i}}$, and the one that maximizes the country-welfare function, i.e. $B^{*}$, in period 2. One qualification is necessary for period 1, because then the expected rent extraction rate is not equal to the actual one. In fact, MNEs are too pessimistic about their business opportunities in countries with low rent extraction and too optimistic in countries with large rent extraction. However, this effect averages out when calculating world-welfare. All together, since the country-welfare function is single-peaked, there must be a world-welfare gain from such an arrangement.

The design exploits two effects: first the BIT regime is one that solves completely the time inconsistency problem but biases the rent extraction rate downward through lobbying of capital owners. A MAI rule such as (28) does not rule out the time inconsistency bias. On the contrary, it exploits this bias to rise the voluntarily chosen rent extraction 
rate towards the world-welfare optimal one. At the same time, the cap at $B^{*}$ ensures that the time inconsistency bias is not too strong to rise the rent extraction rate beyond what is world-welfare optimal. Moreover, the MAI rule (28) ensures that all countries indeed voluntarily join MAI (Corollary 2) such that the cap applies indeed to all countries and prevents thus a time inconsistency bias that is too strong for some countries.

Some remarks on Proposition 5 follow. First of all, the appeal of MAI design (28) is its property to alleviate a national political-economy distortion without touching on the sovereignty of this country. The first best choice of a government whose preferences are distorted relative to world welfare is to find a like-minded partner that guarantees its desired policy. This strategy is only available, however, if some other country with a commitment technology is willing to co-operate. Once this is not the case, such a government enters voluntarily a MAI agreement with design (28) and its own time inconsistency problem drives its policy towards the world-welfare optimal choice.

Second, the suggested rule (28) is not an optimal mechanism. There may be a threshold $B \neq B^{*}$ of a rule such as (28) that is further world-welfare improving. On the contrary, at a threshold value different from $B^{*}$, a world-welfare gain is not guaranteed. If $B$ is larger than $B^{*}$, then the time inconsistency problem may become too severe for too many countries. If $\mathrm{B}$ is smaller than $B^{*}$, some countries may decide not to join and find themselves worth off when compared to a BIT regime. Unfortunately, investigating these issues formally is beyond the scope of this paper.

Finally, although the MAI design (28) is world-welfare superior, there may still be some countries that lose compared to a BIT regime. To see why, note that the MAI rule does not completely resolve the information asymmetry. Countries that choose low rent extraction indirectly subsidize countries that extract more rents, because MNEs have positive ex-post profits in the first group and negative ones in the second. The first group of countries can avoid the subsidy by entering the BIT regime where all informational asymmetries are resolved and country-welfare is improved at the expense of world-welfare. Taking this argument at face value, there is a reason for a "grand bargain" 27 , i.e. the possibility to use investment liberalization as a bargaining chip in exchange for other

\footnotetext{
${ }^{27}$ Hoekman and Saggi (2000) argue for such a "grand bargain".
} 
trade issues to create side-payment instruments to compensate losers by winners.

\section{Model Discussion}

In this section we discuss the robustness of our results. We address in turn the FDI model, the political equilibrium within host countries, and the way MAI is implemented into the model.

\subsection{Robustness of FDI model}

The FDI model is clearly rudimentary and should be best thought of as a reduced form. Crucial for the model is that FDI inflows change relative factor incomes and that factor income as a whole increases through FDI inflows. As pointed out, this hinges crucially on viewing FDI as flow of technology rather than of physical capital. It also hinges on a pure theory of vertical FDI. Markusen (2002) has shown in a model of horizontal and vertical FDI that investment liberalization may indeed be welfare-deteriorating at certain factor endowment combinations. Apart from these restrictions, the FDI model generalizes to general functional forms, as well as different sector settings. More seriously, we have ignored MNE profits that are arguably at the heart of highly-developed-country interests in fostering a MAI. ${ }^{28}$

\subsection{Robustness of political equilibrium}

We have described a rather specific political equilibrium. The lobbying distortion arises exclusively from capital owners. However, trade unions may also exert lobbying power. Moreover, we have ignored monopoly rents of local firms that may be destroyed by FDI inflows thus turning local-firm owners against FDI liberalization. Last but not least, governments may have a genuine interest in maximizing government revenue at the expense of country welfare.

\footnotetext{
${ }^{28}$ We have discussed the implications of an asymmetric distribution of outward FDI in the presence of MNE monopoly rents in a companion paper (Turrini and Urban, 2001).
} 
As a result of all those political distortions in government decision making, there will be a policy that biases rent extraction upward. Hence, there will always be a group of countries that does not join MAI if this upward bias is sufficiently strong. Clearly, outsider governments of MAI still lose and there is a strong incentive of governments that wish to extract the least rents from MNEs to form bilateral agreements and signal their type. Finally, the suggested MAI rule $B^{*}$ is world-welfare improving, since the rent extraction rate will be biased above $B^{*}$ even when resolving the time-inconsistency problem in a BIT regime. Hence, those countries that enter MAI are just kept at the country-welfare optimum $B^{*}$ and those countries that opt out, face investment diversion that erodes their rent extraction rate base and induces them to choose less rent extraction. However, then the political-economy distortion is alleviated even among countries that do not join MAI.

\subsection{Robustness of MAI rule}

Next, we address informally the question why a common maximum standard may be the rule that is agreed upon by a club. There are four reasons for using such a rule. First, a club may try to shift a maximum of welfare from non-members to club members. If the club members are not constrained by the rule, it is very suitable to exert an asymmetric impact on countries.

Second, such a rule is easier to agree to than - say - an equality constraint. After all, all countries that negotiate MAI will be able to choose their optimal policy without any constraints once they accept that one country cannot influence the average perception of MNEs on all future members. In particular, this is the case if there are many countries part of the club that negotiates the agreement. Then, there is no hope for any single country to shape the agreement in its own interest alone.

Third, we have shown in a companion paper that the actual shape of how MAI membership reduces the rent extraction capabilities of host countries may vary substantially and yet produce very similar outcomes. ${ }^{29}$ It is only important that some countries have a relative advantage above others. However, any negotiation of a club is likely to

\footnotetext{
${ }^{29}$ See Turrini and Urban (2001).
} 
yield such an outcome in one way or another.

Finally, we have demonstrated that an inequality rule with a particular cap value entails a world welfare-improving property. If this is the case, then taking such a rule as a starting point of negotiations but manipulating it in the negotiators' interest during the course of the negotiation is easier to obscure from the electorate.

\section{Concluding Remarks}

We have addressed in this study the puzzle why the multilateral investment agreement (MAI) negotiated by the OECD in 1998 was objected by many least developed countries, and eventually failed while at the same time bilateral investment agreements spread out. Our explanation rests on a model where there are three distortions. First, there is a time inconsistency problem that inclines governments to extract too much rents from FDI. Second, we assume that there is an underprovision of public goods which renders at least some rent extraction desirable to finance the provision of public goods. Third, there is a lobbying distortion in the political system. Fixed factor owners (capital) favor FDI inflows and this induces too little rent extraction from FDI. Moreover, the lobbying distortion is hidden information to foreign investors giving rise to political risk. MAI is a device to pre-commit to a certain policy of rent extraction if a group of countries agrees on it.

Any arbitrary club of countries has an incentive to distinguish from countries with larger propensity to rent extraction to redirect FDI towards themselves. This exerts an information externality on outsiders and can explain the protest of some LDCs against MAI negotiation. At the same time, there is a genuine interest of some club members to deviate and form an even stricter agreement among like-minded countries. A system of bilateral investment agreements emerges that reveals government types to MNEs. While this solves the informational distortion in the economy, the political economy distortion remains present. If a MAI design is implemented that excludes bilateral treaties and sets a cap of the rent extraction rate at the welfare-optimal level, then this alleviates the political economy distortion and increases world welfare. Yet, all countries join voluntarily, once these rules are offered. 


\section{A Appendix}

\section{A.1 Appendix 1. Proof of Lemma 1.}

First, the interior solution of $\beta_{i N}$ is zero if for some country $r$,

$$
\chi_{r}=u\left[1+\frac{2 \phi_{r 1 N}}{Y K_{i}}\right] \equiv \chi_{N u}>u
$$

where the inequality follows, since $\phi_{r 1 N}$ is strictly positive by inspection of (4).

Note, second, that $0 \leq \beta_{i N} \leq 1$ by definition of an extraction rate with strict inequality for some $i$. Then, we have

$$
\phi_{i 1 N}=0.5 K_{i}\left(1-E\left[\beta_{i N} \mid N\right]\right) Y<0.5 K_{i} Y \text {. }
$$

Next, we find:

$$
\begin{aligned}
& \frac{\partial \beta_{i N}}{\partial \chi_{i}}=\left\{\begin{array}{cc}
-\frac{u\left[1-\frac{\phi_{i 1 N}}{0.5 Y K_{i}}\right]}{\left(\chi_{i}-2 u\right)^{2}} & \text { if } \\
0 & \chi_{i}<\chi_{N u} \\
0 & \text { else }
\end{array}\right. \\
& \leq 0 \text {, }
\end{aligned}
$$

where the inequality follows from (31). Moreover, for a country $s$ such that $\chi_{s}=1$, holds:

$$
\beta_{s N}=\frac{u+u \frac{\phi_{s 1 N}}{0.5 Y K}-1}{2 u-1}<1
$$

where the inequality follows from (31). (32) and (33) imply $\beta_{i N}<1$ for all $i$.

\section{A.2 Appendix 2: Proof of Lemma 2.}

First, all countries $i$ with a $\beta_{i I} \leq B$ join MAI, since they are not constrained by the rule, but can gain additional FDI inflows by revealing information on their type being liberal to FDI. Next, only countries $i$ with $\beta_{i O}>B$ do not join MAI. Otherwise, they would signal to be of bad quality without exploiting the possibility of violating the MAI rule. This 
implies also that $E\left[\beta_{i O} \mid O\right]>B>E\left[\beta_{i I} \mid I\right]$. But then follows from (5) and (6) that

$$
r_{i 1 I}>r_{i 1 O}
$$

and

$$
r\left(\beta_{i O}\right)>r(B)
$$

for any country $i$. Differentiating the country indifference condition for any $i$ and given $\phi_{i 1 Z}$ yields

$$
\frac{\partial\left[W_{i I}\left(\chi, \beta_{i I}\right)-W_{i O}\left(\chi, \beta_{i O}\right)\right]}{\partial \chi}=\left[r_{i 1 I}+r(B)-r\left(\beta_{i O}\right)-r_{i 1 O}\right] K_{i}>0
$$

where we applied the envelope theorem and the inequality follows from (34) and (35). By assumption, we have

$$
W_{i I}\left(\chi^{*}, \beta_{i I}\right)=W_{i O}\left(\chi^{*}, \beta_{i O}\right)
$$

The inequality (36) and equation (37) together imply the Lemma 2.

\section{A.3 Appendix 3. Proof of Lemma 3.}

We proof (i) first. Assume that there are no constraint countries, i.e. $\chi_{i} \geq \tilde{\chi}$ enters MAI while $\chi_{i}<\tilde{\chi}$ opts out, when a country $\tilde{\varepsilon}$ with $\chi_{\varepsilon}=\tilde{\chi}$ is indifferent, i.e.

$$
W_{\varepsilon I}\left(\tilde{\chi}, \beta_{\tilde{\varepsilon} I}\right)=W_{\tilde{\varepsilon} O}\left(\tilde{\chi}, \beta_{\tilde{\varepsilon} O}\right) .
$$

Then, the optimal choice of $\beta_{i M}$ in a world with MAI is given analogously to (8) by

$$
\beta_{i M}=\left\{\begin{array}{cl}
\frac{\chi_{i}-u}{\chi_{i}-2 u}-\frac{1-E[\beta(i, O) \mid O]}{\chi_{i}-2 u} \text { if } \chi_{i}<\tilde{\chi} \\
\frac{\chi_{i}-u}{\chi_{i}-2 u}-\frac{1-E[\beta(i, I) \mid I]}{\chi_{i}-2 u} \text { if } \tilde{\chi}<\chi_{i}<\chi_{I u} \\
0 & \text { else }
\end{array}\right.
$$


where $\chi_{I u}$ is given by

$$
\chi_{I u} \equiv u\left[2-E\left[\beta_{i I} \mid I\right]\right]
$$

Next, we find that

$$
\phi_{\varepsilon 1 I}>\phi_{\varepsilon 1 O}^{\sim}
$$

by Lemma 2 and equations (4) and (39). From (2) and (40) follows

$$
r_{\tilde{\varepsilon} 1 I}>r_{\tilde{\varepsilon} 1 O}
$$

Moreover, we derive from (7) and the assumption that no country is constrained the expressions

$$
W(\tilde{\varepsilon}, I)=\max _{\beta}\left[\chi_{\varepsilon}^{\sim} r_{\varepsilon 1 I}^{\sim} K_{\varepsilon}^{-}+\chi_{\varepsilon}^{-r}(\beta) K_{\varepsilon}^{-}+u \beta Y \phi_{\varepsilon 1 I}^{\sim}+u \beta Y \phi(\beta)\right]
$$

and

$$
W(\tilde{\varepsilon}, O)=\max _{\beta}\left[\chi_{\varepsilon}^{-r_{\varepsilon, 1, O}} K_{\varepsilon}+\chi_{\varepsilon}^{\sim} r(\beta) K_{\varepsilon}+u \beta Y \phi_{\varepsilon 1 O}^{\sim}+u \beta Y \phi(\beta)\right],
$$

respectively. From (40)-(43) follows that $W(\tilde{\varepsilon}, I)>W(\tilde{\varepsilon}, O)$ which contradicts the assumption (38). Hence, there must exist countries $i$ such that $\chi^{*}<\chi_{i}<\tilde{\chi}$.

For part (ii), we assume to the contrary that $\beta_{i^{*} O}=B$ for the indifferent country $i^{*}$ such that

$$
W\left(i^{*}, O\right)=W\left(i^{*}, I\right) .
$$

By Lemma 2 and equations (4), (6), and (44) we infer that $\phi_{i^{*} 1 I}>\phi_{i^{*} 1 O}$ and $r\left(i^{*}, 1, I\right)>$ $r\left(i^{*}, 1, O\right)$. But then follows under consideration of $(7)$ that

$$
W\left(i^{*}, I\right)-W\left(i^{*}, O\right)=B\left[\phi_{i^{*} 1 I}-\phi_{i^{*} 1 O}\right] Y+r_{i^{*} 1 I}-r_{i^{*} 1 O}>0
$$

which contradicts (44). Since by (i), $\beta_{i^{*} O}$ is constrained, it cannot be smaller than $B$. Hence, (ii) follows. 


\section{A.4 Appendix 4. Proof of Proposition 1.}

Condition (21) is equivalent to

$$
W(1)>0
$$

Next, we find from (4), (11), and (19) that

$$
\beta_{i I}>\beta_{i O}
$$

for all possible interior values of $\chi^{*}$. We conclude from (12) and (47) in turn that there must exist a $\chi^{*}=\chi^{\prime}$ with $\chi^{\prime}<\tilde{\chi}$ such that

$$
\beta_{i O}=B
$$

at $\chi^{*}=\chi^{\prime}$. However, then holds

$$
\begin{aligned}
\tilde{W}\left(\chi^{\prime}\right)= & w\left(E\left[\beta_{i O} \mid O\right], B, \chi^{\prime}\right)-w\left(E\left[\beta_{i I} \mid I\right], B, \chi^{\prime}\right) \\
= & \chi^{\prime}\left[r_{i 1 O}-r_{i 1 I}\right] K_{i} \\
& +u \cdot B \cdot Y \cdot\left[\phi_{i 1 O}-\phi_{i 1 I}\right] \\
< & 0
\end{aligned}
$$

where the inequality follows from (2) and (19). Also $W\left(\chi^{*}\right)<0$ for $\chi^{*}>\chi^{\prime}$. Hence, $W\left(\chi^{*}\right)=0$ can only have an interior solution if $1<\chi^{*}<\chi^{\prime}$. Additionally, the function $W\left(\chi^{*}\right)$ is continuous in the relevant range. Then applies together with (46) and (49) the intermediate value theorem.

Having proven the existence of some interior value of $\chi^{*}$, the Nash conditions can be easily assembled. Countries $\chi_{i}$ have no incentive to deviate from the equilibrium strategy to opt in if and only if $\chi_{i} \leq \chi^{*}$ by Lemma 2 . Firms have no incentive to deviate from their expectation formation in (14) and (16). Otherwise, some firms would make systematically losses, or forgo profit opportunities. And finally, countries have no incentive to deviate from their optimal rent extraction rate choice by construction of the maximization problem 
and Lemma 3.

\section{A.5 Appendix 5. Proof of Corollary 1.}

The function $w(h, h, \chi)$ is quadratic in $h$ and has its peak at $h=(u-\chi) /(2 u-\chi)$. If $u=1$, then the peak is in the negative range that is economically irrelevant and we have from (18) the inequality

$$
h<B<\beta_{i^{*} O}
$$

Next, we investigate the function $w(x, y, \chi)$ that has the properties

$$
\frac{\partial w(h, h, \chi)}{\partial h}<0
$$

and

$$
\frac{\partial w(x, y, \chi)}{\partial x}<0
$$

over the entire range $0 \leq h, x, y \leq 1$ and for any $\chi \geqq 1$. From (11), (13), and (15) follows when assuming an interior solution, i.e. when there is at least one country $i^{*}$ with $\chi_{i^{*}}=\chi^{*}$ and

$$
W\left(\chi^{*}\right)=0,
$$

that the inequality

$$
E\left[\beta_{i O} \mid O\right] \geq \beta_{i^{*} O}>B \geq E\left[\beta_{i I} \mid I\right]
$$

holds. Next, we obtain from the sign of the derivative in (52) the inequalities

$$
w\left(E\left[\beta_{i O} \mid O\right], \beta_{i^{*} O}, \chi^{*}\right)<w\left(\beta_{i^{*} O}, \beta_{i^{*} O}, \chi^{*}\right)
$$

and

$$
w\left(E\left[\beta_{i I} \mid I\right], B, \chi^{*}\right)>w\left(B, B, \chi^{*}\right) .
$$


Likewise, we exploit the sign of the derivative in (51) and the inequality (50) to conclude that

$$
w\left(\beta_{i^{*} O}, \beta_{i^{*} O}, \chi^{*}\right)<w\left(B, B, \chi^{*}\right)
$$

When assembling the inequalities (55), (56), and (57), we have

$$
\begin{aligned}
& w\left(E\left[\beta_{i O} \mid O\right], \beta_{i^{*} O}, \chi^{*}\right)+w\left(\beta_{i^{*} O}, \beta_{i^{*} O}, \chi^{*}\right) \\
< & 2 w\left(\beta_{i^{*} O}, \beta_{i^{*} O}, \chi^{*}\right) \\
< & 2 w\left(B, B, \chi^{*}\right) \\
< & w\left(E\left[\beta_{i I} \mid I\right], B, \chi^{*}\right)+w\left(B, B, \chi^{*}\right)
\end{aligned}
$$

However, inequality (58) implies that

$$
\begin{aligned}
& \tilde{W}\left(\chi^{*}\right) \\
= & w\left(E\left[\beta_{i O} \mid O\right], \beta_{i^{*} O}, \chi^{*}\right)+w\left(\beta_{i^{*} O}, \beta_{i^{*} O}, \chi^{*}\right)-w\left(E\left[\beta_{i I} \mid I\right], B, \chi^{*}\right)-w\left(B, B, \chi^{*}\right)<0
\end{aligned}
$$

for any $\chi^{*}$ which contradicts (53).

\section{A.6 Appendix 6. Proof of Corollary 2.}

Suppose there exists a partial MAI. Then, must hold

$$
W(1)>0
$$

Since from (18), in particular $E\left[\beta_{i O} \mid O\right] \geq \beta_{i O}$, we have that

$$
w\left(\beta_{i O}, \beta_{i O}, 1\right) \geq w\left(E\left[\beta_{i O} \mid O\right], \beta_{i O}, 1\right)
$$

Analogously, from (18), in particular $B^{*} \geq E\left[\beta_{i I} \mid I\right]$, we have that

$$
w\left(B^{*}, B^{*}, 1\right) \geq w\left(E\left[\beta_{i I} \mid I\right], B^{*}, 1\right)
$$


Next we note that $w(h, h, 1)$ is quadratic in $h$ and peaks at

$$
h=\frac{u-1}{2 u-1} \equiv B^{*}
$$

Hence, (63) implies that

$$
w\left(B^{*}, B^{*}, 1\right)>w\left(\beta_{i O}, \beta_{i O}, 1\right)
$$

However, (61), (62), and (64) lead to the inequality

$$
\begin{aligned}
W(1)= & w\left(\beta_{i O}, \beta_{i O}, 1\right)+w\left(E\left[\beta_{i O} \mid O\right], \beta_{i O}, 1\right) \\
& -w\left(B^{*}, B^{*}, 1\right)-w\left(E\left[\beta_{i I} \mid I\right], B^{*}, 1\right) \\
< & 0
\end{aligned}
$$

which contradicts (60). Hence, there cannot exist a partial MAI, where some countries opt in and others out. Since some countries always join MAI and partial MAI does not exist, all countries must join MAI.

\section{A.7 Appendix 7. Proof of Proposition 2.}

We have analogue to equation (17) that

$$
\beta_{i Z}=1-u \frac{E\left[\beta_{i Z} \mid Z\right]}{2 u-\chi_{i}}
$$

for $Z \in\{N, O\}$. Forming expected values yields

$$
E\left[\beta_{i N} \mid N\right]=1-\frac{E\left[\beta_{i N} \mid N\right]}{\bar{\chi}-1} \int_{1}^{\bar{\chi}} \frac{u}{2 u-\chi} d \chi
$$

and

$$
E\left[\beta_{i O} \mid O\right]=1-\frac{E\left[\beta_{i O} \mid O\right]}{\chi^{*}-1} \int_{1}^{\chi^{*}} \frac{u}{2 u-\chi} d \chi
$$


respectively. One can readily see that

$$
\frac{1}{\bar{\chi}-1} \int_{1}^{\bar{\chi}} \frac{u}{2 u-\chi}>\frac{1}{\chi^{*}-1} \int_{1}^{\chi^{*}} \frac{u}{2 u-\chi} d \chi
$$

as $\bar{\chi}>\chi^{*}$. Equations (4), (67), (68), and (69) imply in turn that

$$
\phi_{i 1 N}>\phi_{i 1 O}
$$

Next, the government objective function can be written in the two regimes of a world without MAI $W(i, N)$ and a world, where a country opts out of MAI, $W(i, O)$ as

$$
\begin{aligned}
& W(i, N) \\
& =\max _{\beta}\left[\chi_{i} r\left(\phi_{i 1 N}\right) K_{i}+\chi_{i} r(\beta) K_{i}+u \beta Y \phi_{i 1 N}+u \beta Y \phi(\beta)\right] \\
\equiv & \max _{\beta} W\left(i, \beta, \phi_{i 1 N}\right)
\end{aligned}
$$

and

$$
\begin{aligned}
& W(i, O) \\
= & \max _{\beta}\left[\chi_{i} r\left(\phi_{i 1 O}\right) K_{i}+\chi_{i} r(\beta) K_{i}+u \beta Y \phi_{i 1 O}+u \beta Y \phi(\beta)\right] \\
\equiv & \max _{\beta} W\left(i, \beta, \phi_{i 1 O}\right)
\end{aligned}
$$

where we note that the function $W(i, \beta, \phi)$ applies in both regimes albeit with different arguments. We recall that the functions $r(),. \phi($.$) are defined in (3) and (5), respectively.$ We note that

$$
\frac{\partial W(i, \beta, \phi)}{\partial \phi}>0
$$

Next, we infer from equations and inequalities (70)-(73) that

$$
W(i, O)<W(i, N)
$$


for every country $i$ with $\chi_{i}<\chi^{*}$, when a partial MAI exists with indifferent country $\chi^{*}$. Similarly, we find

$$
\phi_{i 1 N}<\phi_{i 1 I}
$$

and eventually

$$
W(i, I)>W(i, N)
$$

for all countries i with $\tilde{\chi} \leq \chi_{i} \leq \bar{\chi}$.

Finally, we argue why some countries i with $\chi^{*} \leq \chi_{i} \leq \tilde{\chi}$ must lose in a world with MAI relative to a world without MAI. The country $i$ with $\chi_{i}=\chi^{*}$ is indifferent of joining MAI but when it does not join MAI it unambiguously loses according to (74). Hence, it must also lose from a world of MAI when entering MAI. $\square$

\section{A.8 Appendix 8. Proof of Proposition 3.}

Proof of part (i): Consider countries $c$ that form a subgroup of all countries $C$ that negotiate a MAI in a club such that $1<\chi_{c} \leq \chi_{l} \leq \bar{\chi}$ for $c \in C$ and a threshold value $\chi_{l}$. Then, countries $c$ have a government objective value $W(c, C)$ conditional on the group $C$ negotiating an agreement $B(C)$ that can be written as follows:

$$
W(c, C)=\max _{\beta}\left[w\left(E\left[\beta_{c I} \mid B(C), I\right], \beta, \chi_{c}\right)+w\left(\beta, \beta, \chi_{c}\right)\right]
$$

where $E\left[\beta_{c I} \mid B(C), I\right]$ denotes the conditional expected value of the rent extraction rate $\beta$ when knowing the strictness of MAI $B(C)$ and that the country $c$ is MAI member. Then, there exists an alternative agreement among all countries $c^{\prime}$ with $\chi_{c^{\prime}}=\chi_{l}$ and government objective value

$$
W\left(c^{\prime}, c^{\prime}\right)=\max _{\beta}\left[w\left(E\left[\beta_{c^{\prime} I} \mid B\left(c^{\prime}\right), I\right], \beta, \chi_{c^{\prime}}\right)+w\left(\beta, \beta, \chi\left(c^{\prime}\right)\right)\right]
$$

where $E\left[\beta_{c^{\prime} I} \mid B\left(c^{\prime}\right), I\right]=\beta$. By construction must hold

$$
E\left[\beta_{c^{\prime} I} \mid B\left(c^{\prime}\right), I\right]<E\left[\beta_{c I} \mid B(C), I\right] .
$$


Call $\hat{\beta}$ the rent extraction rate that maximizes $W(c, C)$, i.e.

$$
\hat{\beta}=\arg \max \left[w\left(E\left[\beta_{c I} \mid B(C), I\right], \beta, \chi_{c}\right)+w\left(\beta, \beta, \chi_{c}\right)\right] .
$$

Inequality (79) together with the property $d w(x, y, \chi) / d x>0$ implies

$$
\begin{aligned}
W\left(c^{\prime}, C\right) & \equiv w\left(E\left[\beta_{c^{\prime} I} \mid B(C), I\right], \hat{\beta}, \chi_{c^{\prime}}\right)+w\left(\hat{\beta}, \hat{\beta}, \chi_{c^{\prime}}\right) \\
& <w\left(E\left[\beta_{c^{\prime} I} \mid B\left(c^{\prime}\right), I\right], \hat{\beta}, \chi_{c^{\prime}}\right)+w\left(\hat{\beta}, \hat{\beta}, \chi_{c^{\prime}}\right) \\
& <\max _{\beta}\left[w\left(E\left[\beta_{c^{\prime} I} \mid B\left(c^{\prime}\right), I\right], \beta, \chi_{c^{\prime}}\right)+w\left(\beta, \beta, \chi_{c^{\prime}}\right)\right] \\
& \equiv W\left(c^{\prime}, c^{\prime}\right)
\end{aligned}
$$

Hence, there is an incentive for a subgroup of $\mathrm{C}$ to deviate from the commonly negotiated contract.

Proof of part (iii): consider a BIT of countries $c$ with $\chi_{c}=\chi$. Then Proposition 3 and equation (26) yield a negotiated strictness of MAI of $B(\chi)=(u-\chi) /(2 u-\chi)$.

Proof of part (ii): From part (i) follows that there exists an incentive of some subgroup to deviate from any MAI that is negotiated by a group of countries $\mathrm{C}$ heterogeneous in $\chi$. Consider the following algorithm: of any possible group $\mathrm{C}$ the countries $c^{\prime}$ with $\chi_{c^{\prime}}=\chi_{l}$, form an own MAI. Applying this step to all possible groups $C$ yields a system of investment treaties for each different value of $\chi$. There is no incentive to deviate from such a system, since $B(\chi)$ is the rent extraction rate that maximizes the government objective function of all countries $c$ with lobbying term $\chi_{c}=\chi$.

\section{A.9 Appendix 9. Proof of Proposition 5.}

Call $U(i \mid A)$ country i welfare at the MAI regime under rule $B^{*}$ and $U(i \mid B)$ the country welfare under the BIT regime, respectively. By Corollary 2, all countries $i$ join MAI under rule (28). Then, we have

$$
U(i \mid A)=w\left(E\left[\beta_{i I} \mid I\right], \beta_{i I}, 1\right)+w\left(\beta_{i I}, \beta_{i I}, 1\right)
$$


and

$$
U(i \mid B)=2 w\left(\frac{u-\chi_{i}}{2 u-\chi_{i}}, \frac{u-\chi_{i}}{2 u-\chi_{i}}, 1\right),
$$

respectively. (i) We recall that $d w(x, y, \chi) / d x<0$.(ii) The function $w(h, h, 1)$ has the property of single-peakedness with peak $h=(u-1) /(2 u-1)=B^{*}$. From rule $(28)$ and optimal $\beta$ choice of a country within MAI follows

$$
\beta_{i I}=\max \left[\frac{u-\chi_{i}}{2 u-\chi_{i}}+\frac{u\left(1-E\left[\beta_{i I} \mid I\right]\right)}{\left[2 u-\chi_{i}\right]}, B^{*}\right] \equiv \beta(\chi, I)
$$

Hence, we have the ranking

$$
\frac{u-\chi_{i}}{2 u-\chi_{i}} \leq \beta_{i I} \leq B^{*}
$$

and

$$
\frac{u-\chi_{i}}{2 u-\chi_{i}} \leq E\left[\beta_{i I} \mid I\right] \leq B^{*}
$$

with at least one strict inequality for some $\chi_{i}$. Next, we find

$$
w\left(\frac{u-\chi_{i}}{2 u-\chi_{i}}, \frac{u-\chi_{i}}{2 u-\chi_{i}}, 1\right)<w\left(E\left[\beta_{i I} \mid I\right], E\left[\beta_{i I} \mid I\right], 1\right)
$$

and

$$
w\left(\frac{u-\chi_{i}}{2 u-\chi_{i}}, \frac{u-\chi_{i}}{2 u-\chi_{i}}, 1\right)<w\left(\beta_{i I}, \beta_{i I}, 1\right)
$$

by applying property (ii) of the function $w($.$) and inequalities (85) and (86). World welfare$ in a world with MAI rule $B^{*}$, i.e. $U(A)$, and world welfare in a regime of $\operatorname{BITs} U(B)$ are the aggregates of all countries' welfare conditional on the regimes given in (82) and (83). 
Hence, we can conclude

$$
\begin{aligned}
U(A) & \equiv \int U(i \mid A) d i \\
& =\int_{1}^{\bar{\chi}} w\left(E\left[\beta_{i I} \mid I\right], \beta(\chi, I), 1\right)+w(\beta(\chi, I), \beta(\chi, I), 1) d \chi \\
& =(\bar{\chi}-1) w\left(E\left[\beta_{i I} \mid I\right], E\left[\beta_{i I} \mid I\right], 1\right)+\int_{1}^{\bar{\chi}} w(\beta(\chi, I), \beta(\chi, I), 1) d \chi \\
& =\int_{1}^{\bar{\chi}} w\left(E\left[\beta_{i I} \mid I\right], E\left[\beta_{i I} \mid I\right], 1\right)+w(\beta(\chi, I), \beta(\chi, I), 1) d \chi \\
& >\int_{1}^{\bar{\chi}} 2 w\left(\frac{u-\chi_{i}}{2 u-\chi_{i}}, \frac{u-\chi_{i}}{2 u-\chi_{i}}, 1\right) d \chi \\
& =\int_{U(i \mid B) d i} \\
& \equiv U(B),
\end{aligned}
$$

where the first equality uses Corollary 2, the second equality follows, since $y$ enters linear in the function $w(x, y, \chi)$ and the law of large numbers is applied, and the inequality follows from (87) and (88). 


\section{References}

[1] Bagwell, K., Staiger, R. W., 1999. An economic theory of GATT. American Economic Review 89 (1), 215-48.

[2] Barry, F., Bradley, J., 1997. FDI and trade: the Irish host-country experience. The Economic Journal 107, 1798-1811.

[3] Black, D., Hoyt, W., 1989. Bidding for firms. American Economic Review 79, 12491256.

[4] Brecher, R.A., Díaz-Alejandro, C.F., 1977. Tariffs, foreign capital, and immiserizing growth. Journal of International Economics 7, 317-322.

[5] Brunetti, A., Weder, B., 1998. Investment and institutional uncertainty: a comparative study of different uncertainty measures. Review of World Economics 134 (3), 513-33.

[6] Burgess, N., Stern, N., 1993. Taxation and development. Journal of Economic Literature $31,762-830$.

[7] Devereux, M.P., Griffith, R., 1998. Taxes and the location of production: evidence from a panel of US multinationals. Journal of Public Economics 68, 335-367.

[8] Doyle, C., van Wijnbergen, S., 1994. Taxation of foreign multinationals: a sequential bargaining approach to tax holidays. International Tax and Public Finance 1, 211-225.

[9] Drabek, Z., 1998. A multilateral agreement on investment: convincing the sceptics. ERAD Staff Working Paper No. 98-05.

[10] Eaton, J., Gersovitz, M., 1984. A theory of expropriation and deviations from perfect capital mobility. The Economic Journal 94, 16-40.

[11] Ethier, W., 1998. Regionalism in a multilateral world. Journal of Political Economy 106 (6), 1214-1245. 
[12] Facchini, G., Willmann, G., 2005. The political economy of international factor mobility. Journal of International Economics 67, 201-219.

[13] Feenstra, R.C., Hanson, G.H., 1996. Foreign investment, outsourcing, and relative wages, in: Feenstra, R.C. , Grossman, G.M., Irwin, D.A. (Eds.), The Political Economy of Trade Policy: Papers in Honor of Jagdish Bhagwati. MIT Press, Cambridge MA, pp. 89-127.

[14] Feenstra, R.C., Hanson, G.H., 1997. Foreign direct investment and relative wages: evidence from Mexico's maquiladoras. Journal of International Economics 42, 371393.

[15] Fernandez-Arias, E., Spiegel, M.M., 1998. North-South customs unions and international capital mobility. Journal of International Economics 46, 229-251.

[16] Fumagalli, C., 2000. On the welfare effects of competition for foreign direct investments. C.E.P.R. Discussion Paper No. 2468.

[17] Ganesan, A.V., 1998. Developing countries and a possible multilateral framework on investment: strategic options. Transnational Corporations 7 (2), 1-38.

[18] Gastanaga, V.M., Nugent, J.B., Pashamova, B., 1998. Host country reforms and FDI inflows: how much difference do they make? World Development 26 (7), 1299-1314.

[19] Grossman, G.M., Helpman, E., 1994. Protection for sale. American Economic Review 84, 833-50.

[20] Grossman, G.M., Helpman, E., 1996. Foreign investment with endogenous protection, in: Feenstra, R.C. , Grossman, G.M., Irwin, D.A. (Eds.), The Political Economy of Trade Policy: Papers in Honor of Jagdish Bhagwati. MIT Press, Cambridge MA, pp. 199-223.

[21] Haaland, J., Wooton, I., 1999. International competition for multinational investment. Scandinavian Journal of Economics 101, 631-649. 
[22] Haaparanta, P., 1996. Competition for foreign direct investments. Journal of Public Economics 63, 141-153.

[23] Haufler, A., Wooton, I., 1999. Country size and tax competition for foreign direct investment. Journal of Public Economics 71, 121-139.

[24] Helpman, E., 1984. A simple theory of international trade with multinational corporations. Journal of Political Economy 92 (3), 451-71.

[25] Hines Jr., J.R., Rice, E.M., 1994. Fiscal paradise: foreign tax havens and American business. Quarterly Journal of Economics 109 (1), 149-182.

[26] Hoekman, B., Saggi, K., 2000. Multilateral disciplines for investment-related policies, in: Guerrieri, P., Eckart-Scharrer, H. (Eds.), Global Governance, Regionalism, and the International Economy. Nomos Verlagsgesellschaft, Baden-Baden, pp. 167-191.

[27] Janeba, E., 2002. Attracting FDI in a politically risky world. International Economic Review 43 (4), 1127-1155.

[28] Jun, K.W., Singh, H., 1996. The determinants of foreign direct investment in developing countries. Transnational Corporations 5 (2), 67-105.

[29] Krugman, P.R., 2000. Technology, trade and factor prices. Journal of International Economics 50, 51-70.

[30] Lee, J.-Y., Mansfield, E., 1996. Intellectual property protection and U.S. foreign direct investment. The Review of Economics and Statistics 78 (2), 181-186.

[31] Lucas, R., 1990. Why doesn't capital flow from rich to poor countries? American Economic Review 80 (2), 92-96.

[32] Markusen, J., 1995. The boundaries of multinational enterprises and the theory of international trade. Journal of Economic Perspectives 9, 169-189.

[33] Markusen, J., 2001. Commitment to rules on investment: the developing countries' stake. Review of International Economics 9, 287-302. 
[34] Markusen, J., 2002. Multinational Firms and the Theory of International Trade, MIT Press, Cambridge MA.

[35] Murphy, K., Shleifer, A., Vishny, R., 1989. The big push. Journal of Political Economy 97, 1003-1026.

[36] OECD, 1998. The multilateral agreement on investment. Draft consolidated text, DAFFE/MAI(98)7/REV1, OECD, Paris, available on www1.oecd.org/daf/mai/pdf/ng987r1e.pdf.

[37] Raff, H., 1992. A model of expropriation with asymmetric information. Journal of International Economics 33, 245-265.

[38] Reinhart, C.M., Rogoff, K.S., 2004. Serial default and the "paradox" of rich-to-poor capital flows. American Economic Review 94 (2), 53-58.

[39] Schnitzer, M., 1999. Expropriation and control rights: a dynamic model of foreign direct investment. International Journal of Industrial Organization 17, 1113-1137.

[40] Schnitzer, M., 2002. Debt v. foreign direct investment: the impact of sovereign risk on the structure of international capital flows. Economica 69, 41-67.

[41] The Economist, 1998. Trade by any other name. November 3.

[42] Thomas, J., Worall, T., 1994. Foreign direct investment and the risk of expropriation. Review of Economic Studies 61, 81-108.

[43] Turrini, A., Urban, D., 2001. For Whom is MAI? A Theoretical Perspective on Multilateral Agreements on Investment. C.E.P.R. Discussion Paper No. 2774.

[44] UNCTAD, 1998, 1999. World Investment Report. United Nations, New York and Geneva.

[45] Wei, S.-J., 2000. How taxing is corruption on international investors? The Review of Economics and Statistics 82 (1), 1-11. 


$\begin{array}{llllll} & & & & & \\ & & & & & \\ \text { determining } & \text { determining } & \text { country MAl } & \text { MNE } & \text { government } & \text { MNE } \\ \text { group of } & \text { strictness of } & \text { membership } & \text { location } & \text { rent } & \text { re-location } \\ \text { negotiating } & \text { MAl } & \text { choice } & \text { choice } & \text { extraction } & \text { choice } \\ \text { countries } & & & \text { choice } & \\ & & & \text { subject to } & \\ & & & \text { MAl membership } \\ & & & \text { constraint }\end{array}$

Figure 1: Sequencing of Events

Figure 1:

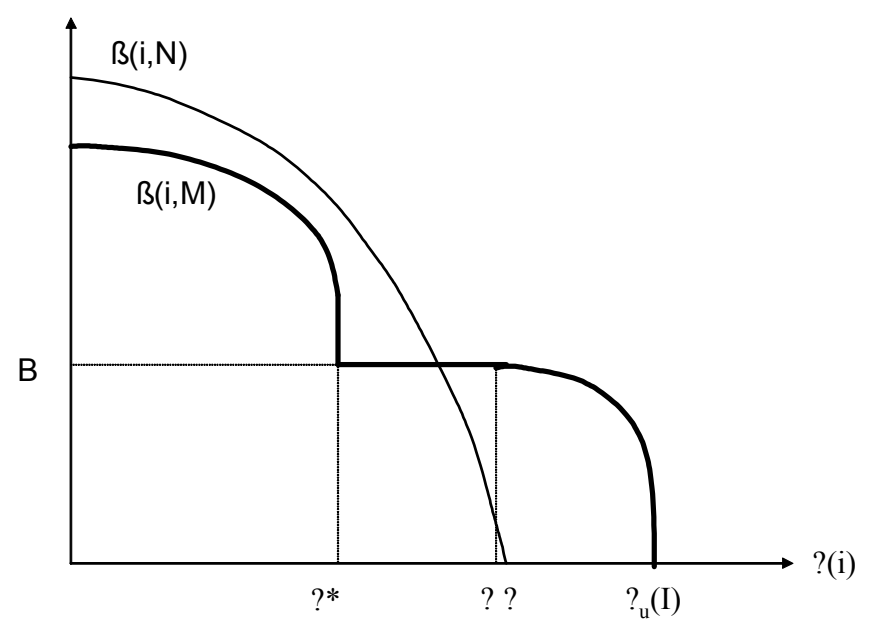

Figure 2: Optimal rent extraction rate choice

Figure 2: 